\title{
Buckling of spherical concrete shells
}

\author{
by Emad Zolqadr \\ Bachelor’s Degree, Civil Engineering-Civil, Mohaghegh Ardabili University, 2008 \\ Master of Science, Geotechnical Engineering, Tarbiat Modares University, 2011
}

\author{
An MRP \\ presented to Ryerson University \\ in partial fulfillment of the \\ requirements for the degree of \\ Master of Engineering \\ in the program of \\ Civil Engineering
}

Toronto, Ontario, Canada, 2017

(C) Emad Zolqadr, 2017 


\section{AUTHOR'S DECLARATION}

I hereby declare that I am the sole author of this MRP. This is a true copy of the MRP, including any required final revisions.

I authorize Ryerson University to lend this MRP to other institutions or individuals for the purpose of scholarly research.

I further authorize Ryerson University to reproduce this MRP by photocopying or by other means, in total or in part, at the request of other institutions or individuals for the purpose of scholarly research.

I understand that my MRP may be made electronically available to the public.

Emad Zolqadr 


\section{Buckling of spherical concrete shells}

Emad Zolqadr, Master of Engineering, Civil Engineering, 2017

Ryerson University

\section{ABSTRACT}

This study is focused on the buckling behavior of spherical concrete shells (domes) under different loading conditions.

The background of analytical analysis and recommended equations for calculation of design buckling pressure for spherical shells are discussed in this study.

The finite element (FE) method is used to study the linear and nonlinear response of spherical concrete shells under different vertical and horizontal load combination buckling analysis. The effect of different domes support conditions are considered and investigated in this study.

Several dome configurations with different geometry specifications are used in this study to attain reliable results. The resulted buckling pressures from linear FE analysis for all the cases are close to the analytical equations for elastic behavior of spherical shells. The results of this study show that geometric nonlinearity widely affects the buckling resistance of the spherical shells.

The effect of horizontal loads due to horizontal component of earthquake is not currently considered in the recommended equation by The American Concrete Institute (ACI) to design spherical concrete shells against buckling. However, the results of this study show that horizontal loads have a major effect on buckling pressure and it could not be ignored. 


\section{TABLE OF CONTENTS}

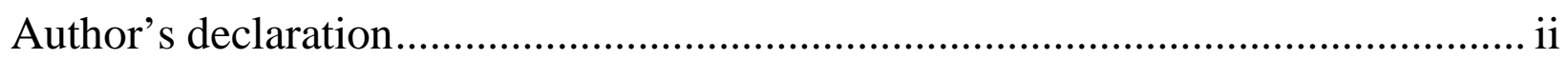

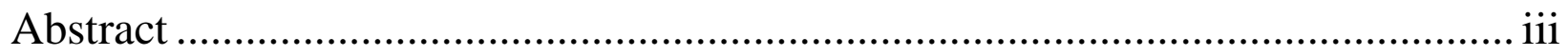

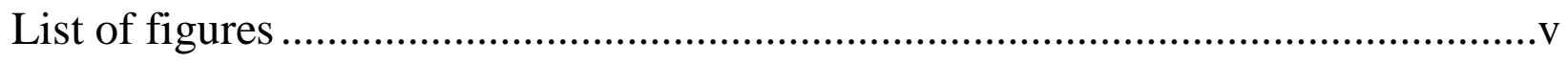

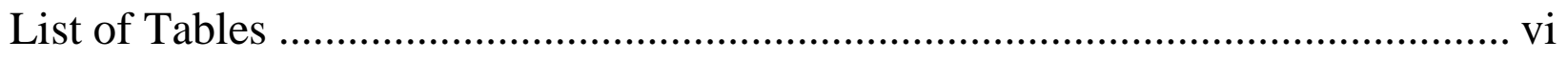

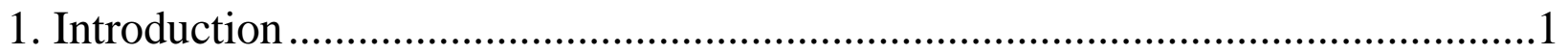

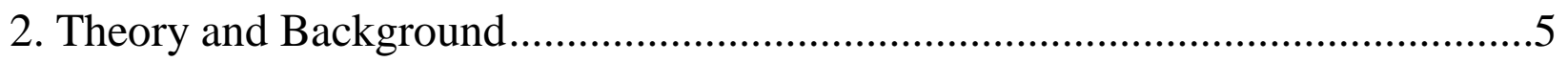

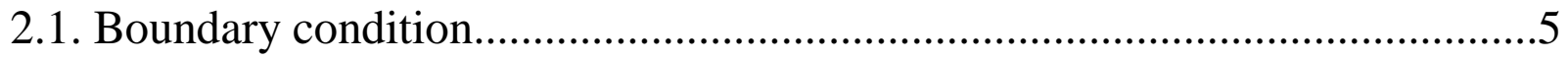

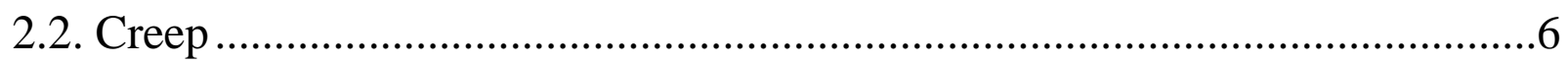

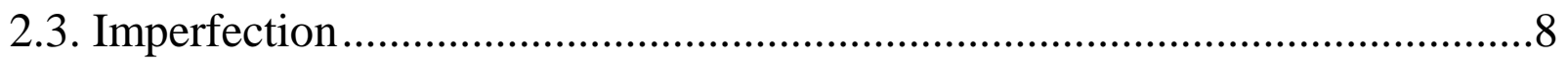

2.4. ACI recommendation for Dome design........................................................11

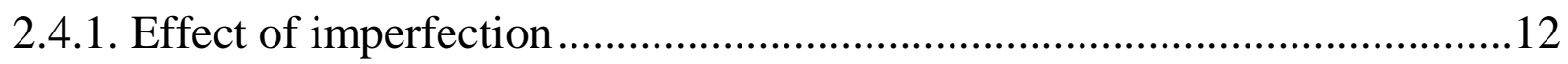

2.4.2. Effects of creep and material nonlinearity and cracking ...........................12

2.4.3. Load Combination ..................................................................................14

3. Finite Element Analysis for buckling of concrete domes...................................15

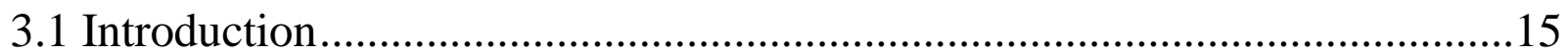

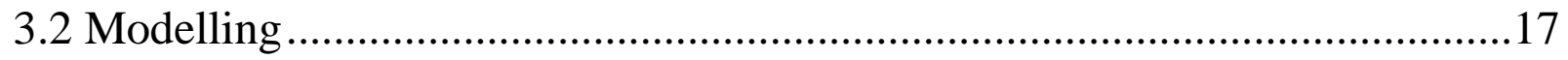

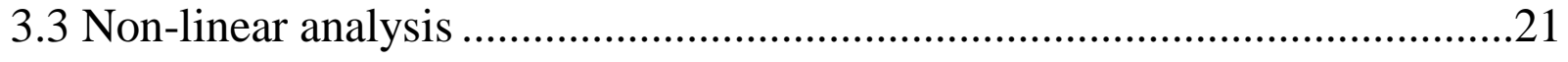

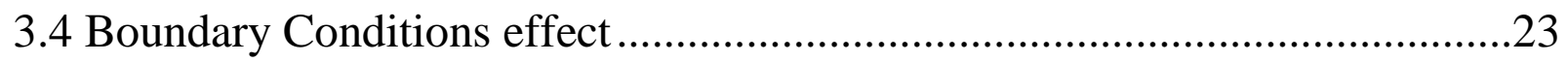

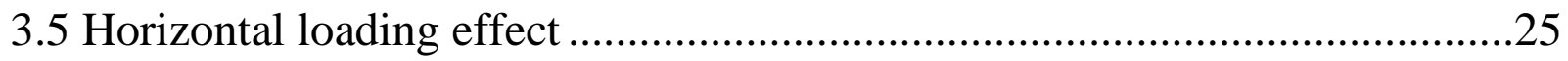

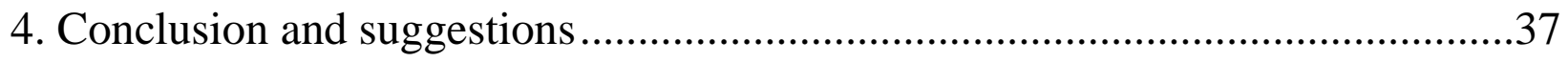

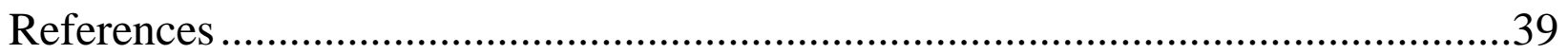




\section{List of figures}

Fig 1. Geometry of spherical dome .......................................................................

Fig 2. Effect of initial imperfection (Krenzke and Thomas, 1965)..........................4

Fig 3. Effect of boundary condition (Huang, 1964) .................................................

Fig 4. Creep versus thickness of concrete domes ..................................................7

Fig 5. Reduction factor for buckling strength of a shallow spherical concrete shell due to material nonlinearity, creep and cracking........................................................

Fig 6. Effect of $\Delta \boldsymbol{h} \boldsymbol{a}$ on the Elastic Buckling Coefficient, $\mathrm{K}$................................

Fig 7. Calculate buckling pressure of clamped shallow spherical shells and experimental results .......................................................................................... 10

Fig 8. Geometry of imperfection .....................................................................10

Fig 9. Vertical deformation of the center point -Nonlinear analysis- Dome 7 7....22

Fig 10. First buckling mode under self-weight (DL)- Dome 7................................25

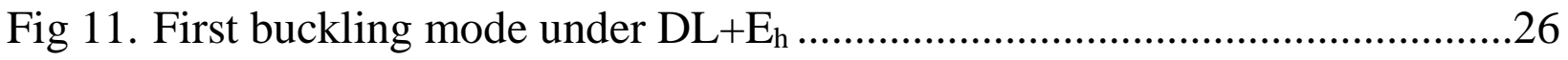

Fig 12. First buckling mode under $E_{h}$................................................................26

Fig 13. Resulted buckling pressure vs $\mathrm{F}_{\mathrm{EH}}-$ Horizontal loading- Dome 1 and 2 .....28

Fig 14. Resulted buckling pressure vs $\mathrm{F}_{\mathrm{EH}}-$ Horizontal loading- Dome 3 and 4 .....29

Fig 15. Resulted buckling pressure vs $\mathrm{F}_{\mathrm{EH}}-$ Horizontal loading- Dome 5 and 6 .....29

Fig 16. Resulted buckling pressure vs $\mathrm{F}_{\mathrm{EH}}-$ Horizontal loading- Dome 7 and 8 .....30

Fig 17. Resulted buckling pressure vs $\mathrm{F}_{\mathrm{EH}}-$ Horizontal loading- Dome 9 and 10 ...30

Fig 18. Resulted buckling pressure vs $\mathrm{F}_{\mathrm{EH}}-$ Horizontal loading- Dome 11 and 12.31

Fig 19. Resulted buckling pressure vs $\mathrm{F}_{\mathrm{EH}}-$ Horizontal loading- Dome 13 and 14.31

Fig 20. Resulted buckling pressure vs $\mathrm{F}_{\mathrm{EH}}$-Horizontal loading + Self-weight Dome 1 and 2 .33

Fig 21. Resulted buckling pressure vs $\mathrm{F}_{\mathrm{EH}}$-Horizontal loading + Self-weight Dome 3 and 4 .33

Fig 22. Resulted buckling pressure vs $\mathrm{F}_{\mathrm{EH}}$-Horizontal loading + Self-weight Dome 5 and 6 
Fig 23. Resulted buckling pressure vs $\mathrm{F}_{\mathrm{EH}}$-Horizontal loading + Self-weight Dome 7 and 8

Fig 24. Resulted buckling pressure vs $\mathrm{F}_{\mathrm{EH}}$-Horizontal loading + Self-weight Dome 9 and 10 ...... .35

Fig 25. Resulted buckling pressure vs $\mathrm{F}_{\mathrm{EH}}$-Horizontal loading + Self-weight Dome

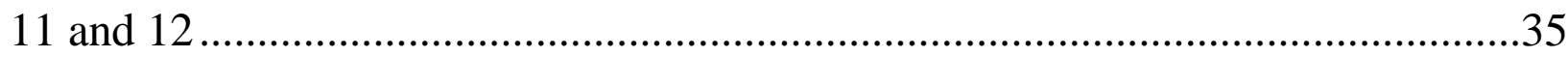

Fig 26. Resulted buckling pressure vs $\mathrm{F}_{\mathrm{EH}}$-Horizontal loading + Self-weight Dome 13 and 14 .36

\section{List of Tables}

Table 1. Geometry of the studied spherical concrete shells..................................18

Table 2. Classical Buckling Pressure and SAP2000 results ................................19

Table 3. Non-linear Buckling Pressure .................................................................22

Table 4. The effect of boundary condition ...........................................................23

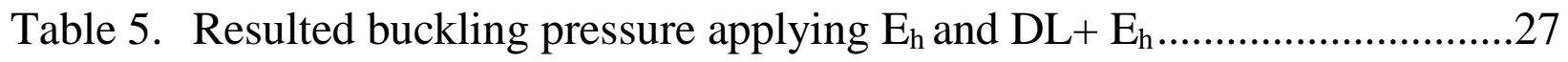

Table 6. Resulted $\mathrm{K}_{1}$-Linear analysis applying $\mathrm{E}_{\mathrm{h}}$..............................................32

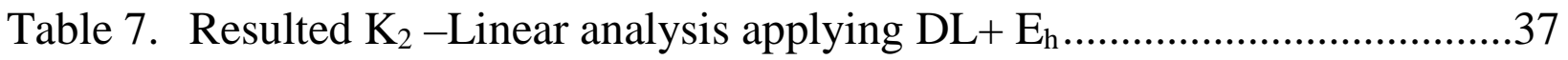




\section{Introduction}

For a thin shell made from linear elastic materials, buckling will occur at nominal stress states that may be far below yielding. Timoshenko and Gere (1963) summarized the classical small-deflection theory for the elastic buckling of a complete sphere as first developed by Zoelly (1915). This analysis assumes that buckling will occur at that pressure which permits an equilibrium shape minutely removed from the perfectly spherical deflected shape and it is assumed that the buckled surface is symmetrical with respect to a diameter of the sphere. The elastic buckling coefficients corresponding to the minimum pressure required to keep an elastic shell in the post-buckling position.

The expression for this Classical Buckling Pressure $\left(\mathrm{P}_{0}\right)$ is given as;

$$
P_{0}=\frac{2 E\left(\frac{h}{R}\right)^{2}}{\sqrt{3\left(1-v^{2}\right)}}\left[\begin{array}{ll}
E q & 1
\end{array}\right]
$$

For Poisson ration of $0.2 ; P_{0}=1.18 E\left(\frac{h}{R}\right)^{2}$

For Poisson ration of $0.3 ; P_{0}=1.21 E\left(\frac{h}{R}\right)^{2}$

Where:

E: Elastic modulus of concrete (MPa)

h: Shell thickness (m)

$\mathrm{R}$ : Shell curve radius (m)

$v$ : Poisson ratio 
Based on Krenzke and Thomas (1965), the available data prior to this analysis do not support the linear theory. The elastic buckling loads of roughly one-fourth those predicted by Equation [1] were observed in earlier tests recorded in the literature. The test specimens used in the earlier tests by Fung, and Seckler (1960 and Klöppel, and Jungbluth (1953), which their results have frequently been compared to the theoretical buckling pressures for initially perfect spheres, were formed from flat plates and it can be assumed that these early specimens had significant departures from sphericity as well as variations in thickness and residual, stresses and adverse boundary conditions.

Comparing with the classical buckling pressure, Krenzke and Thomas (1965) and Buchnell (1966) suggested three reasons for the lower experimentally obtained buckling pressure; the possibility of unsymmetrical, disturbance in the uniform membrane stress due to edge support conditions, and imperfections in the fabrication/construction of the spherical shape.

Various investigators have attempted to explain this discrepancy by introducing nonlinear, large deflection shell equations. In effect, their expressions for the theoretical buckling pressures resulting from the nonlinear equations take the same general form as Equation [1]. 


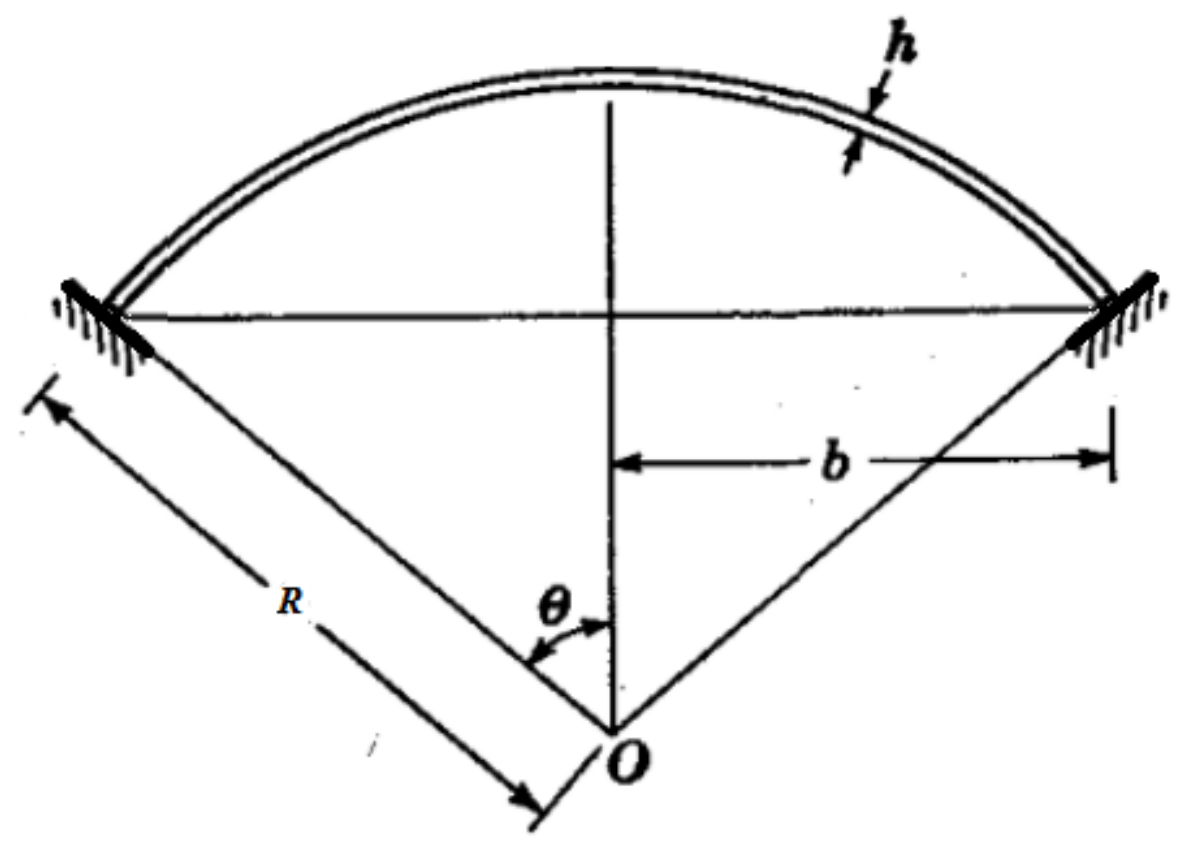

Fig 1. Geometry of spherical dome

For practical applications Kloppel and Jungbluth suggested the following empirical formula for calculating critical buckling pressure which gives satisfactory results for $400 \leq \frac{R}{h} \leq 2000$ and $20 \leq \theta \leq 60^{\circ}$ (Timoshenko and Gere, 1963):

$$
P_{c r}=\left(1-0.175 \frac{\theta-20}{20}\right)\left(1-\frac{\frac{0.07 R}{h}}{400}\right)(0.3 E)\left(\frac{h}{R}\right)^{2}[E q 2]
$$

Krenzke and Thomas (1965) reported that for machined shells which more closely fulfilled the assumptions of classical theory, the collapse strength of these shells was about two to four times greater than the collapse strength of the shells formed from flat plates and it reached to 90 percent of classical elastic buckling pressure. These results indicate that the classical buckling load coefficient is apparently valid for perfect spheres. However, it is impossible to manufacture or measure most spherical shells with sufficient accuracy to justify the use of the classical equation in design. 
Fig. 2 illustrates that no single budding coefficient may be used in Equation [1] to calculate the strength of spherical shells which have varying degrees of initial imperfections.

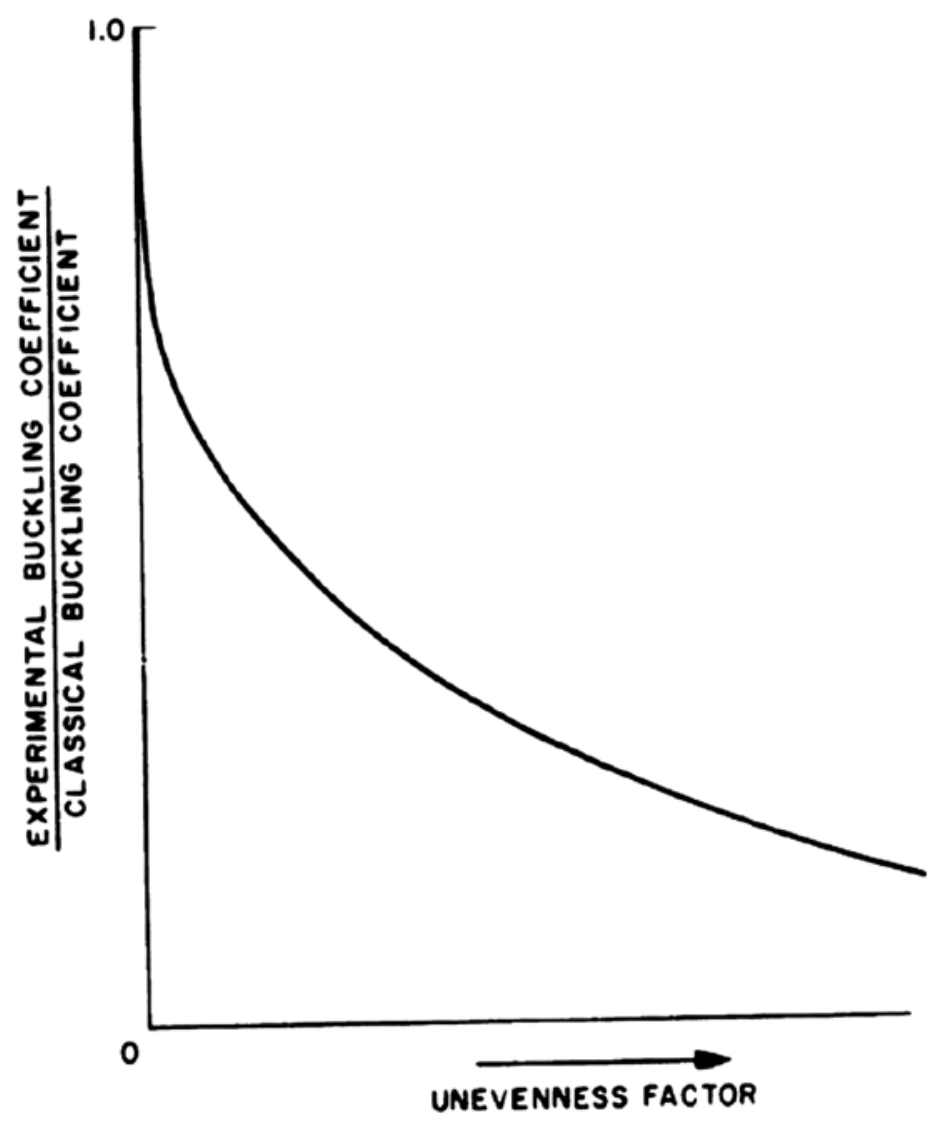

Fig 2. Effect of initial imperfection (Krenzke and Thomas, 1965)

Based on the test results, Krenzke and Thomas (1965) suggest an empirical equation for near- perfect spheres was suggested which predicts collapse to occur at about 0.7 times the classical pressure. This Empirical Equation for the elastic buckling pressure $\mathrm{P}$ of near-perfect spheres may be expressed as:

$$
P_{1}=\frac{1.4 E\left(\frac{h}{R}\right)^{2}}{\sqrt{3\left(1-v^{2}\right)}} \quad[E q 3]
$$




\section{Theory and Background}

\subsection{Boundary condition}

A theoretical study by Huang (1964) indicates that the critical buckling load of clamped spherical shells is lower than that for shell with radially free boundary condition. Therefore, it would be conservative to calculate of the radially free boundary shall by that of a clamped shallow shell having the same radius of curvature. Fig. 3 shows the buckling load for a spherical shell with boundaries that are clamped, hinged, or free to displace radially.

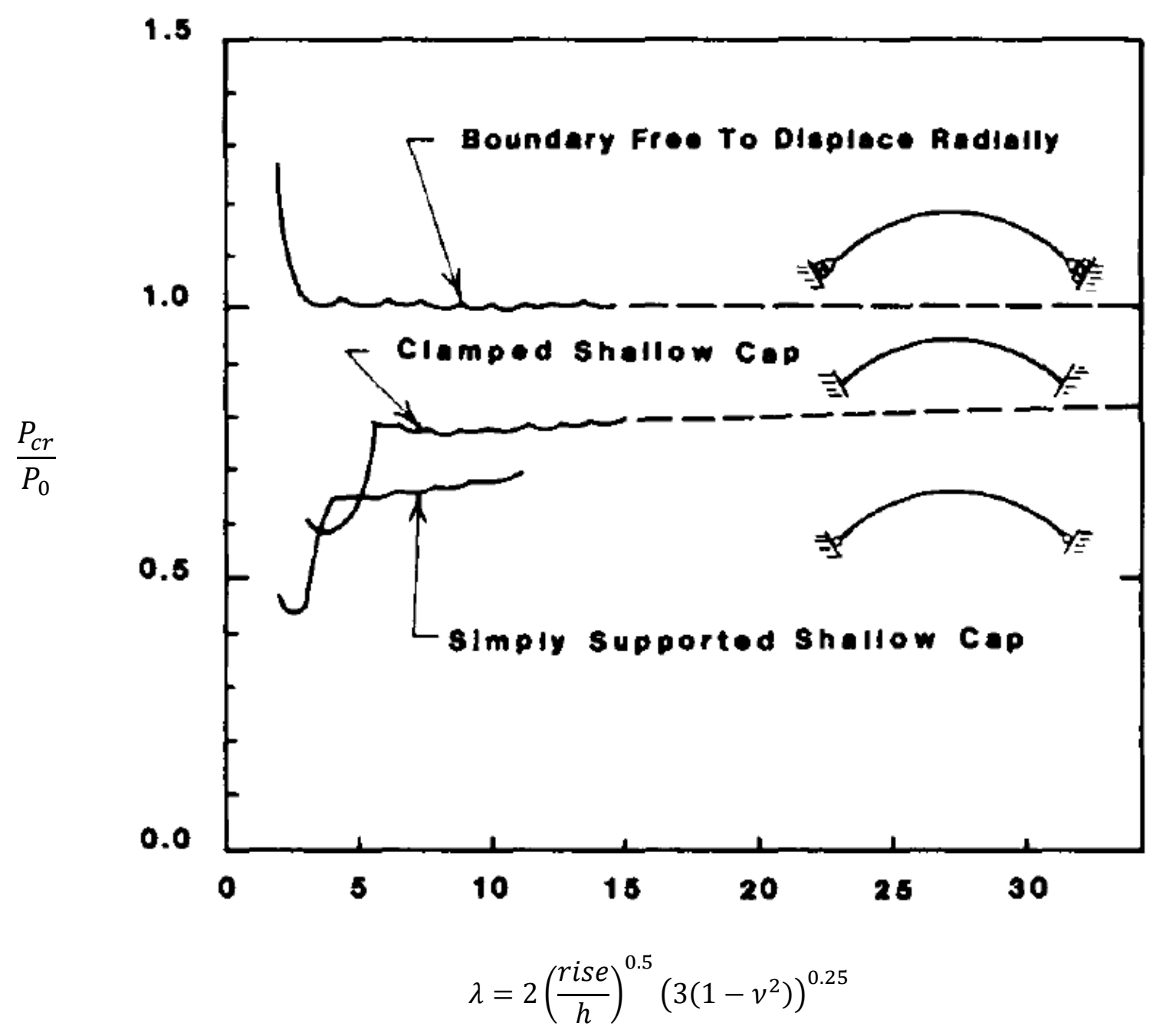

Fig 3. Effect of boundary condition (Huang, 1964) 


\subsection{Creep}

The creep buckling load of spherical shells is a highly sensitive function of initial geometric imperfections.

Fig. 4 presents creep versus thickness of a concrete dome located in an environment with an annual average outside relative humidity of 50 percent (arid), 70 percent (humid), and inside relative humidity of 100 percent and loaded after 28 days with 25. $9 \mathrm{MPa}$.

The creep factor under the dead load and the snow load can be selected from Fig. 4 after correcting the dead load creep for the age of concrete at the time of loading if different from 28 days.

From the dead-load and snow load components of creep, the buckling reduction factor $\beta_{c}$ due to creep, material nonlinearity, and cracking of concrete can be selected from Fig. 5 based on the selected creep factor from Fig. 4. 


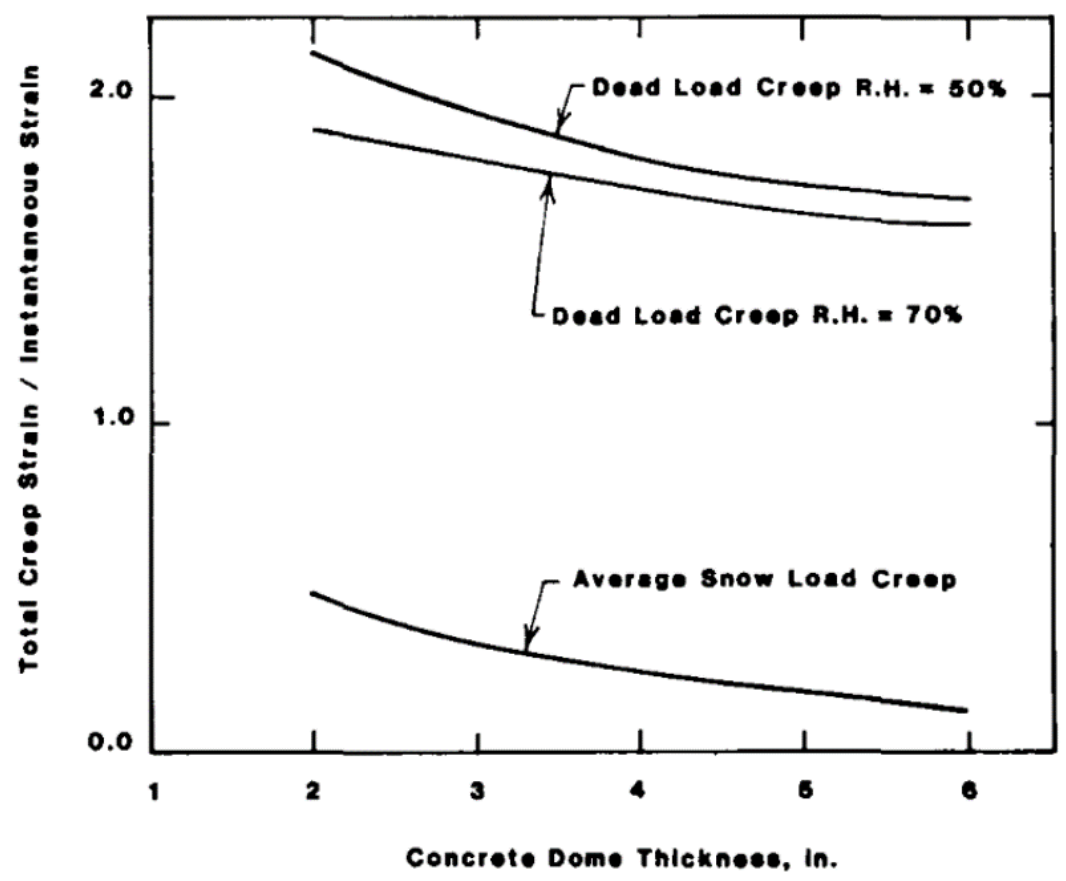

Fig 4. Creep versus thickness of concrete domes (Zarghamee and Heger, 1983)

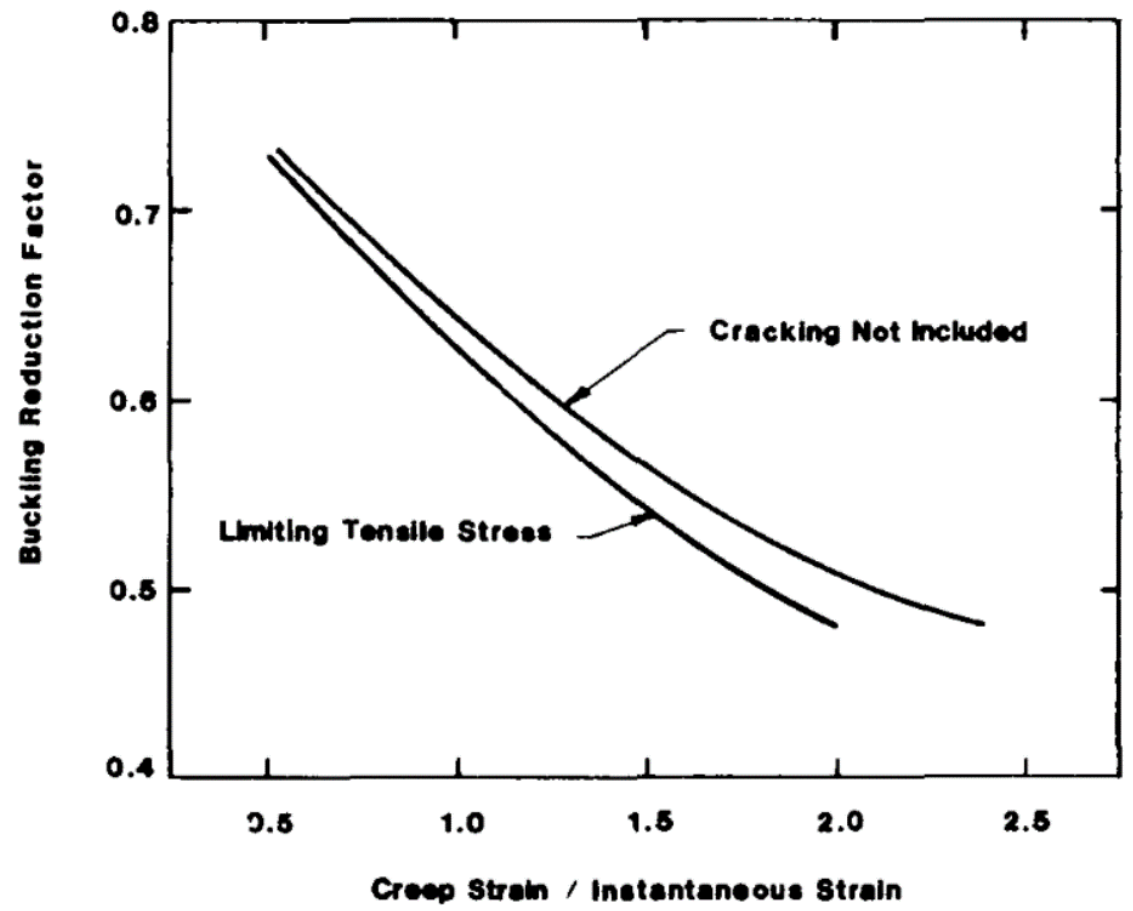

Fig 5. Reduction factor for buckling strength of a shallow spherical concrete shell due to material nonlinearity, creep and cracking (Zarghamee and Heger, 1983) 


\subsection{Imperfection}

The effect of initial deviations from sphericity is extremely important in the elastic buckling case since the local radius appears in the appropriate equation to the second power. To demonstrate this effect in more familiar terminology, the elastic buckling coefficient K for $v$ of 0.3 is plotted against $\frac{\Delta}{h_{a}}$ in Fig. 6. The Empirical Equation may be rewritten in terms of nominal radius as;

$$
P_{1}=K E\left(\frac{h_{a}}{R}\right)^{2}[E q 4]
$$

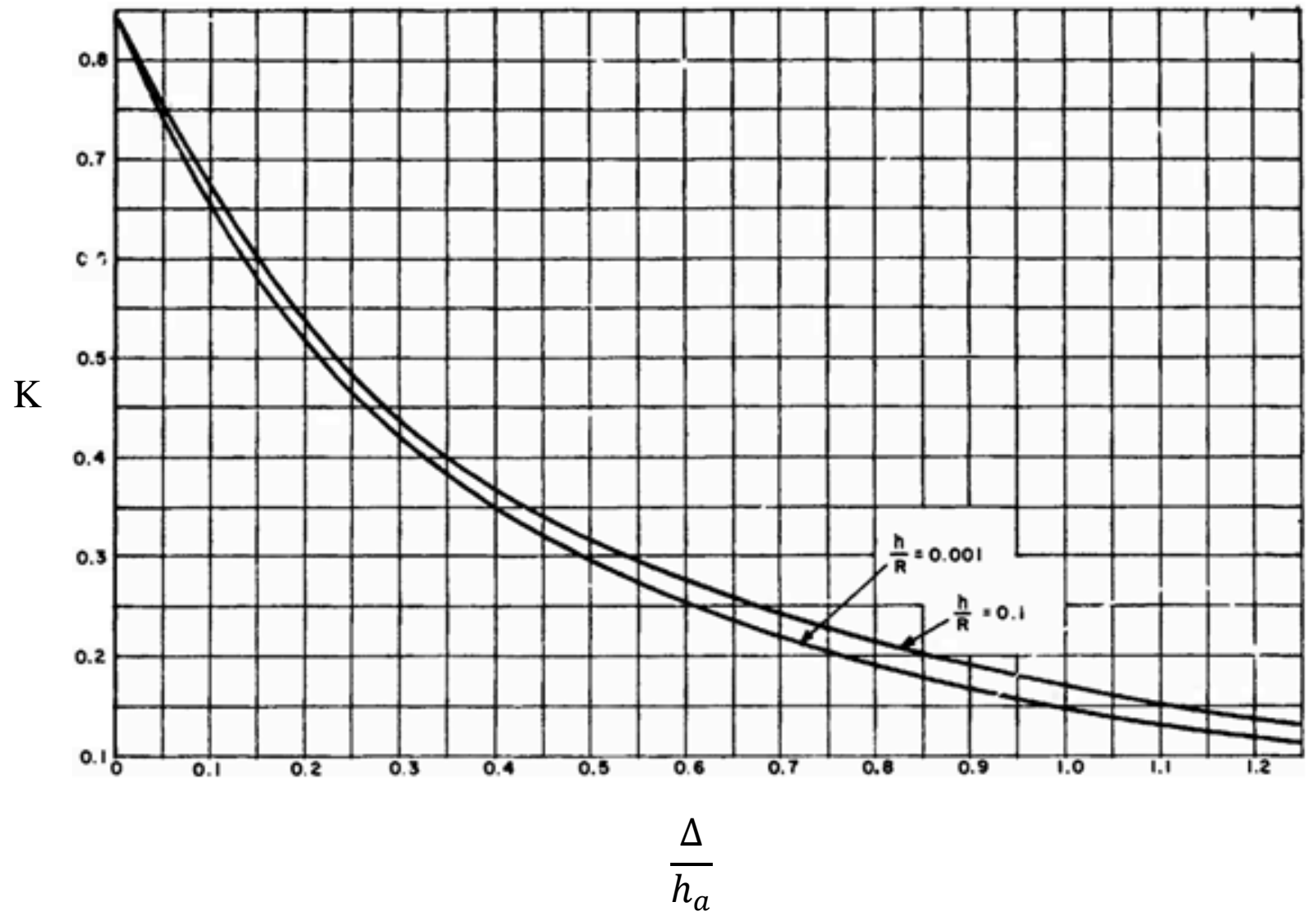

Fig 6. Effect of $\frac{\Delta}{h_{a}}$ on the Elastic Buckling Coefficient, K (Krenzke and Thomas, 1965)

Where:

$h_{a}$ : the average thickness over a critical length

$\Delta:$ out - of - roundness 
As it is discussed by Zarghamee and Heger (1983) the critical buckling load of a spherical shell is severely affected by deviations from its perfectly spherical shape that result in a significant change of $\mathrm{R} / \mathrm{h}$ over a large enough region of the order of magnitude of a buckle size.

Imperfections, which are the cause of the discrepancy between the experimental results and those computed based on the classical theory, result from instantaneous deformations, creep deformations, and manufacturing tolerances. The effect of imperfections caused by instantaneous deformation is included in nonlinear buckling analyses. Imperfections caused by creep and manufacturing tolerances are responsible for observed deviations of the experimental results from those obtained through nonlinear analyses.

Considering the effect of initial imperfections is also very important when calculating the inelastic buckling strength where the collapse pressure is primarily a function of the average stress level.

For a linear elastic material with no time-dependent properties, the buckling strength of a clamped spherical cap is shown in Fig. 7, where $n$ is the number of waves along the circumferential direction in the buckling mode.

Based on Huang (1964) almost all concrete domes with practical dimensions fall in the region of $\lambda>5.5$, making non-axisymmetric buckling an important consideration. The ratio $\left(\mathbf{p}_{\mathbf{c r}} / \mathbf{p}_{\mathbf{0}}\right)$ of the critical buckling pressure to the classical buckling pressure approaches 0.864 as $\lambda$ approaches infinity.

The least resistant spherical cap is the one with a shallowness parameter $\lambda=4$, computed based on an average radius of curvature in the imperfection region. 


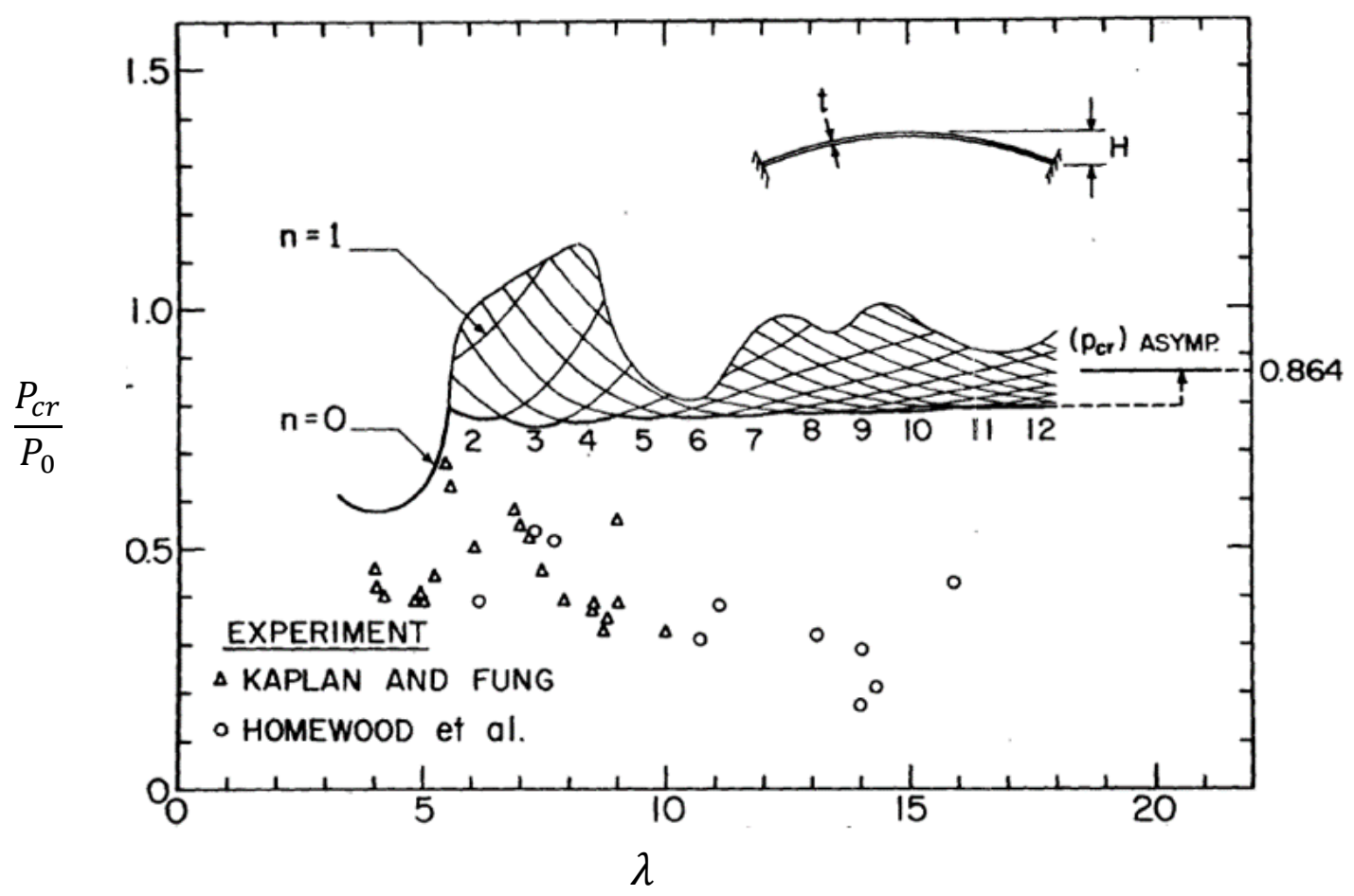

Fig 7. Calculate buckling pressure of clamped shallow spherical shells and experimental results (Huang, 1964)

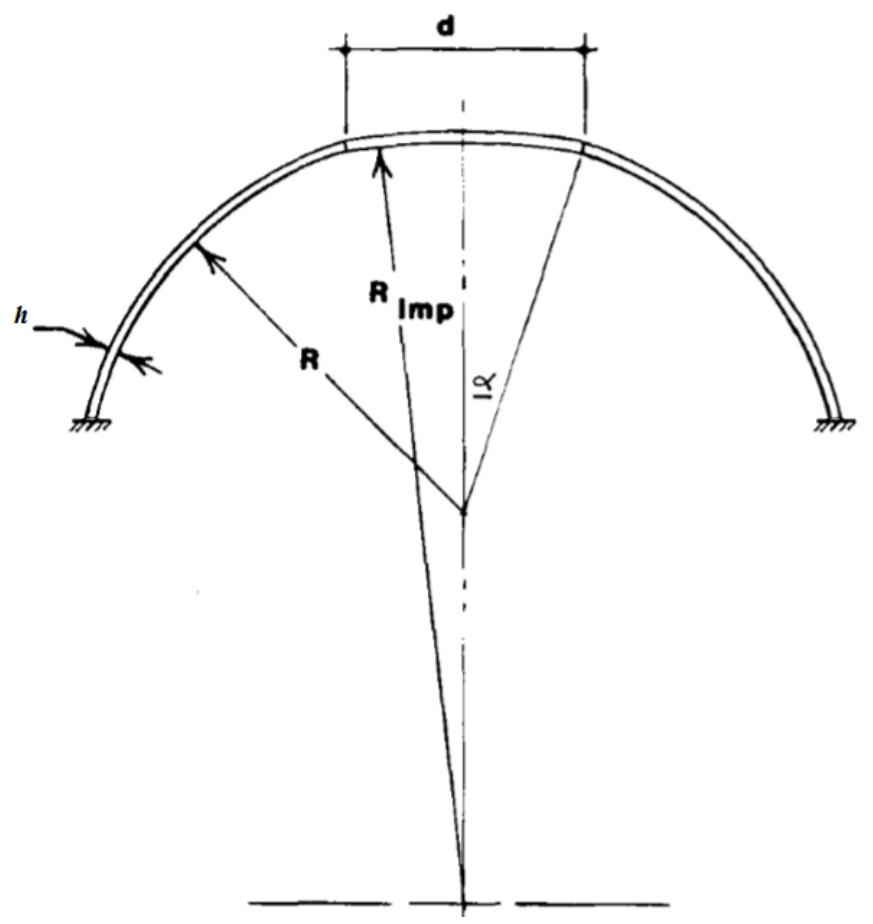

Fig 8. Geometry of imperfection 
The diameter of the imperfection corresponding to $\lambda=4$ is $d=4.3 \sqrt{R_{i m p} t}$, where $R_{i m p}$ and $t$ are the average radius of curvature and the average thickness of the dome over the imperfection region. The buckling load of a clamped spherical cap with $\lambda=4$ is $\mathrm{Pa}=0.66 \mathrm{E}(\mathrm{t} / \mathrm{R})^{2}$ which is the base of the equation that is suggested by ACI 372R-13.

\subsection{ACI recommendation for Dome design}

The current suggested equation (3.4.2.2a) by ACI 372R-13 is based on the equation that is presented in Zarghamee and Heger (1983). The only deference between them is a parameter for vertical component of earthquake forces. It should be noted that in the previous version, ACI 372R-03, there was not any consideration for seismic loads in the equation.

The dome minimum thickness:

$$
h_{d}=r_{d} \sqrt{\frac{1.5}{\phi \beta_{i} E}\left(\frac{p_{u}}{\beta_{c}}+E_{v}\right)}[E q 5]
$$

The equation, ignoring Imperfection, creep, material nonlinearity, and cracking may be expressed as:

$$
\begin{gathered}
h_{d}=r_{d} \sqrt{\frac{1.5}{E}\left(p_{u}+E_{v}\right)} \\
0.66 E\left(\frac{h_{d}}{r_{d}}\right)^{2}=p_{u}+E_{v}
\end{gathered}
$$

Which is equal to $55 \%$ of Classical Buckling pressure for $v=0.2$ and it is similar to what is suggested by Huang (1964). 
To consider the effects of variability of concrete properties, imperfection, and creep of concrete some buckling reduction factors are considered based on results of the results of practical experiments.

The capacity reduction factor equal to $\phi=0.7$ is suggested to account for the variability of concrete properties, dome construction, and accuracy of buckling analysis.

\subsubsection{Effect of imperfection}

Based on the works of Bushnell, Krenzke and Kiernan, and Huang, assume that the buckling strength of this shell is governed by the lowest buckling load of the imperfection regions, each assumed to be clamped at its boundary.

The reduction factor for imperfection defined based on the ratio of dome radius (R) to its thickness $(\mathrm{t})$.

$$
\beta_{i}=\left(\frac{\frac{\mathrm{R}}{\mathrm{t}}}{\left(\frac{R}{t}\right) \max }\right)^{2}[E q 6]
$$

The value for the reduction factor of buckling strength due to imperfections would be around $\beta_{i}=0.5$ if the average radius of curvature $\mathrm{R}_{\mathrm{imp}}$ measured over a region of diameter $\mathrm{d}=2.5 \sqrt{R t}$ is not more than $1.4 \mathrm{R}$, where $\mathrm{R}$ is the nominal radius of curvature; otherwise, ignoring thickness imperfection, it can be calculated as;

$$
\beta_{i}=\left(\mathrm{R} / \mathrm{R}_{\mathrm{imp}}\right)^{2} \quad[E q 7]
$$

\subsubsection{Effects of creep and material nonlinearity and cracking}

For an elastic shallow spherical cap, creep is expected to reduce the buckling strength of the shell considerably. Thin domes creep significantly even when they 
are subjected to live loads, such as snow loads that are assumed to act for a onemonth duration.

A reduction factor of 0.6 on the creep strain was used to account for the age of concrete at the time of live load application for domes built on water tanks.

The effect of creep strain on the reduction of the buckling strength of a concrete dome is predicted by a nonlinear analysis that includes the simultaneous-effects of creep, geometric nonlinearity, and stress-strain nonlinearity.

Select a buckling reduction factor $\beta_{C}$, due to creep, material nonlinerarity, and cracking of concrete by obtaining the creep factor under the dead load and the snow load as;

Based on the design live load, select a value for reducing buckling strength of the dome due to creep, material nonlinearity, and cracking as follows:

$$
\beta_{C}=\left\{\begin{array}{cl}
0.44+0.003(L L) & \text { for } 0.57 \leq L L<1.44 \\
0.53 & \text { for } L L \geq 1.44
\end{array}\right.
$$

Where LL is in $\mathrm{kPa}$.

If an existing dome has been designed for less than $0.57 \mathrm{kPa}$ live load, the reduction factor for buckling strength becomes a function of thickness which may be expressed as:

$$
\beta_{C}=0.476+\left(\frac{0.005 h}{25.4}-0.046\right)\left(1-\left(\frac{L L}{12} * 0.048\right)\right) \quad[E q 9]
$$

Where $\mathrm{LL}$ is in $\mathrm{kPa}$ and $\mathrm{h}$ is in $\mathrm{mm}$. 


\subsubsection{Load Combination}

The coefficients for dead load DL, , snow load SL, live load LL, and vertical component of earthquake load $E_{\mathrm{v}}$ in deferent load combinations are recommended for use in dome design by ACI 372R-13 as;

$\mathrm{U}_{1}=1.4 \mathrm{D}$

$\mathrm{U}_{2}=1.2 \mathrm{D}+1.6 \mathrm{~L}$

$\mathrm{U}_{3}=1.2 \mathrm{D}+0.2 \mathrm{~S}+\mathrm{E}_{\mathrm{v}}$

However, as it is discussed before the horizontal component of earthquake is not considered in the recommended equation in ACI 372R-13 for calculation of the minimum thickness of the spherical concrete shells against buckling pressure. 


\section{Finite Element Analysis for buckling of concrete domes}

\subsection{Introduction}

In the current study, some Linear Finite Element Analysis for buckling of spherical concrete shells have been performed using a FE computer program, SAP2000 (CSI 2008).

Developed by Computers and Structures, Inc., SAP2000 is a three-dimensional nonlinear analysis program boasting an intuitive interface allowing for several types of structural analyses. Among its broad range of capabilities, SAP2000 provides options for applying incremental static loads, quasi-static cyclic loads (cyclic loads varying slowly with time), combinations of horizontal and vertical excitations, inelastic dynamic analyses, as well as general purpose hysteretic models.

SAP2000 provides an interactive and graphical technique and allows a model to be created easily by producing the geometry into mesh able regions. Material properties, loads, and boundary conditions can be assigned to the geometry.

Buckling occurs physically when a structure becomes unstable under a given loading configuration, and mathematically when a bifurcation occurs in the solution to equations of static equilibrium. The two primary means for performing buckling analysis include Eigenvalue and Nonlinear buckling analyses. Buckling must be explicitly evaluated for each set of loads considered because, unlike natural frequencies, buckling modes are dependent upon a given load pattern.

When evaluating buckling, any number of load cases may be defined, each of which should specify loading, convergence tolerance, and the number of modes to be found. Since the first few buckling modes may have similar factors, in this study a minimum of six modes have been considered for each analysis. 
Nonlinear analysis methods are best applied when either geometric or material nonlinearity is considered during structural modeling and analysis. If only elastic material behavior is considered, linear analysis methods should suffice, though PDelta formulation may still be applied. In the current study, generally linear analysis method is applied. The effect of non-linear analysis is considered in section 3.3,

When large stresses are present within a structure, equilibrium equations written for the original and the de formed geometries may differ significantly, even if the de formations are very small. In the case of Large-displacement effect, when a structure undergoes large deformation (in particular, large strains and rotations), the usual engineering stress and strain measures no longer apply, and the equilibrium equations must be written for the de formed geometry. This is true even if the stresses are small.

Nonlinear buckling may be evaluated in SAP2000 using Nonlinear static analysis. This procedure takes an iterative approach while implementing P-Delta and LargeDisplacement effect. Structural response is shown by plotting selected joint displacements against load application. A softening behavior may be observed in this plot, indicating the onset of buckling, and the condition of instability which follows.

During Nonlinear-static buckling analysis, the total load is applied incrementally. Stiffness and response are evaluated at each increment. Between each displacement step, stiffness may change due to the P-Delta effect, LargeDisplacement, and Nonlinear material behavior effects. P-Delta effect, which involves large tensile or compressive stresses on transverse bending and shear behavior. Large-Displacement effect, in which deformed configuration is considered when assembling the equilibrium equations. Nonlinear material behavior is ignored in the current analysis. 


\subsection{Modelling}

The properties and geometries of the models are considered based on 14 concrete domes covering wide range of practical cases. Both linear and nonlinear behavior of the cases, are considered in the analysis. Since the shell thickness is significantly smaller than its area, using thin shell elements to model the domes is considered appropriate. In this case, the element thickness is defined through the section property definition.

Shell elements are used to model the spherical concrete shells. A shell is a three or four-node area object used to model membrane and plate-bending behavior. Shell objects are useful for simulating floor, wall, and bridge deck systems; 3D curved surfaces; and components within structural members, such the web and flanges of a W-Section.

Shells may be homogeneous or layered throughout their thickness. Temperaturedependent, orthotropic, and nonlinear material properties may be assigned to layered shells. Shells may be assigned edge constraints, and may be loaded in any direction, along any side.

For all cases, the spherical shell are clamped and the edge of the domes are fixed for displacements and rotations. The unit weight of the concrete material is considered equal to $23.92 \mathrm{kN} / \mathrm{m}^{3}$. The elastic modulus of the concrete is $28862 \mathrm{MPa}$ and the Poisson ratio is equal to 0.16 . The geometry of the cases are presented in Table 1. 
Table 1. Geometry of the studied spherical concrete shells

\begin{tabular}{|c|c|c|c|c|}
\hline Model & $\mathrm{R}(\mathrm{m})$ & Rise $(\mathrm{m})$ & $\theta\left(^{\circ}\right)$ & $\mathrm{h}(\mathrm{mm})$ \\
\hline 1 & 27.22 & 1.09 & 16.22 & 76 \\
\hline 2 & 54.43 & 2.18 & 16.22 & 76 \\
\hline 3 & 25.35 & 1.17 & 17.46 & 76 \\
\hline 4 & 50.7 & 2.34 & 17.45 & 76 \\
\hline 5 & 76.05 & 3.52 & 17.46 & 102 \\
\hline 6 & 88.73 & 4.1 & 17.45 & 102 \\
\hline 7 & 39.62 & 3.05 & 22.59 & 102 \\
\hline 8 & 59.44 & 4.57 & 22.59 & 89 \\
\hline 9 & 69.34 & 5.33 & 22.59 & 95 \\
\hline 10 & 64.77 & 7.62 & 28.04 & 95 \\
\hline 11 & 80.96 & 9.53 & 28.04 & 114 \\
\hline 12 & 97.16 & 11.43 & 28.04 & 146 \\
\hline 13 & 113.35 & 13.34 & 28.04 & 190 \\
\hline 14 & 129.54 & 15.24 & 28.04 & 235 \\
\hline
\end{tabular}

The linear buckling analysis have performed for all the cases presented in Table 1, under uniform vertical loads. As presented in Table 2, the results of models of the domes are close to the classical buckling pressure for all the cases. Based on Krenzke and Thomas (1965) classical buckling pressure equation is valid for perfect spherical shells.

Classical buckling pressure:

$$
P_{0}=\frac{2 E\left(\frac{h}{R}\right)^{2}}{\sqrt{3\left(1-v^{2}\right)}}[E q 10]
$$

$v=0.16 \rightarrow P_{0} \approx 1.17 E\left(\frac{h}{R}\right)^{2}$ 
Where:

E: Elastic modulus of concrete (MPa)

h: Shell thickness (m)

$\mathrm{R}$ : Shell curve radius (m)

$v$ : Poisson ratio

Table 2. Classical Buckling Pressure and SAP2000 results

\begin{tabular}{|c|c|c|}
\hline Model & Eq 1 (MPa) & SAP2000 (MPa) \\
\hline 1 & 264.67 & 67.26 \\
\hline 2 & 66.17 & 317.79 \\
\hline 3 & 305.05 & 77.39 \\
\hline 4 & 76.25 & 60.9 \\
\hline 5 & 60.25 & 70.08 \\
\hline 6 & 69.17 & 224.78 \\
\hline 7 & 221.97 & 75.83 \\
\hline 8 & 75.53 & 63.82 \\
\hline 9 & 63.7 & 72.25 \\
\hline 10 & 73.01 & 66.52 \\
\hline 11 & 67.29 & 75.53 \\
\hline 12 & 76.3 & 94.69 \\
\hline 13 & 95.37 & 110.38 \\
\hline 14 & 111.06 & \\
\hline
\end{tabular}

Considering the reduction factors suggested by Zarghamee and Heger (1983) the critical Buckling Pressure can be calculated from the following equation: 


$$
P_{c r} \approx 0.66 \phi \beta_{i} \beta_{c} E\left(\frac{h}{R}\right)^{2}[E q 11]
$$

Where:

$\phi$ : Capacity reduction factor

$\beta_{i}$ : Imperfection reduction factor

$\beta_{c}$ : Creep, material nonlinearity and cracking reduction factor

The capacity reduction factor equal to $\phi=0.7$ is suggested to account for the variability of concrete properties, dome construction, and accuracy of buckling analysis.

Assuming $\beta_{i}=0.5$ for reduction factor of buckling strength due to imperfections and $\beta_{C}=0.6$ for reduction factor due to creep and material nonlinearity and cracking, the critical Buckling Pressure would reduce to about $12 \%$ of the Classical Buckling Pressure $\left(0.66 \phi \beta_{i} \beta_{c} / 1.17\right)$ and it may be calculated as;

$$
P_{c r} \approx 0.14 E\left(\frac{h}{R}\right)^{2}[E q 12]
$$

The vertical component of the earthquake has similar effect as uniform vertical loads on the buckling pressure resulted by linear finite element analysis because it is applied as coefficient of the self-weight of the domes. However, since the earthquake is a short-term load, as it suggested by ACI 372R-13, for calculation of the critical buckling pressure it is not affected by reduction factor due to creep $\left(\beta_{C}\right)$. 


\subsection{Non-linear analysis}

As it is discussed in part 2.3., the effect of imperfection should be considered in buckling pressure analysis. The effect of P- $\Delta$ and large displacement effects on buckling pressure are analyzed for all cases by Non-linear analysis using SAP2000. The effect of material non-linearity is not considered in current analysis.

To perform a nonlinear static analysis of the spherical concrete shells with SAP2000, models of the domes are first created as if it were a linear-elastic static analysis cases.

As it presented in the Table 3, the resulted buckling pressure decreased up to 55\% in compare with the linear analysis results.

Generally the sensitivity of the resulted buckling pressure to non-linearity decrease with increment of the thickness of the spherical shells (h). For cases with the same thickness, the domes with smaller radius (R) show less sensitivity to nonlinearity.

The graph in Fig. 9 presents vertical deformation of center point (Crest) of model 7 , resulted by nonlinear analysis under distributed vertical loading. As it is presented, the center point continues to settle, increasing the vertical distributed load up to about $75 \mathrm{kPa}$. Because of starting of the first mode of buckling, the center point begins to move up increasing the vertical distributed load before failing at the load of $91.75 \mathrm{kPa}$. 
Table 3. Non-linear Buckling Pressure

\begin{tabular}{|c|c|c|c|}
\hline Model & $\begin{array}{c}\mathrm{P}_{0}(\mathrm{MPa}) \\
\text { Linear }\end{array}$ & $\begin{array}{c}\mathrm{P}_{0}(\mathrm{MPa}) \\
\text { Non-Linear }\end{array}$ & $\begin{array}{c}\text { Reduction } \\
(\%)\end{array}$ \\
\hline 1 & 274.65 & 114 & 41.51 \\
\hline 2 & 67.26 & 37 & 55.01 \\
\hline 3 & 317.79 & 129.5 & 40.75 \\
\hline 4 & 77.39 & 40.75 & 52.65 \\
\hline 5 & 60.9 & 24.75 & 40.64 \\
\hline 6 & 70.08 & 22.5 & 32.1 \\
\hline 7 & 224.78 & 91.75 & 40.82 \\
\hline 8 & 75.83 & 30.02 & 39.59 \\
\hline 9 & 63.82 & 25 & 39.17 \\
\hline 10 & 72.25 & 28.75 & 39.79 \\
\hline 11 & 66.52 & 24.25 & 36.46 \\
\hline 12 & 75.53 & 17 & 22.51 \\
\hline 13 & 94.69 & 17.75 & 18.75 \\
\hline 14 & 110.38 & 16.25 & 14.72 \\
\hline
\end{tabular}

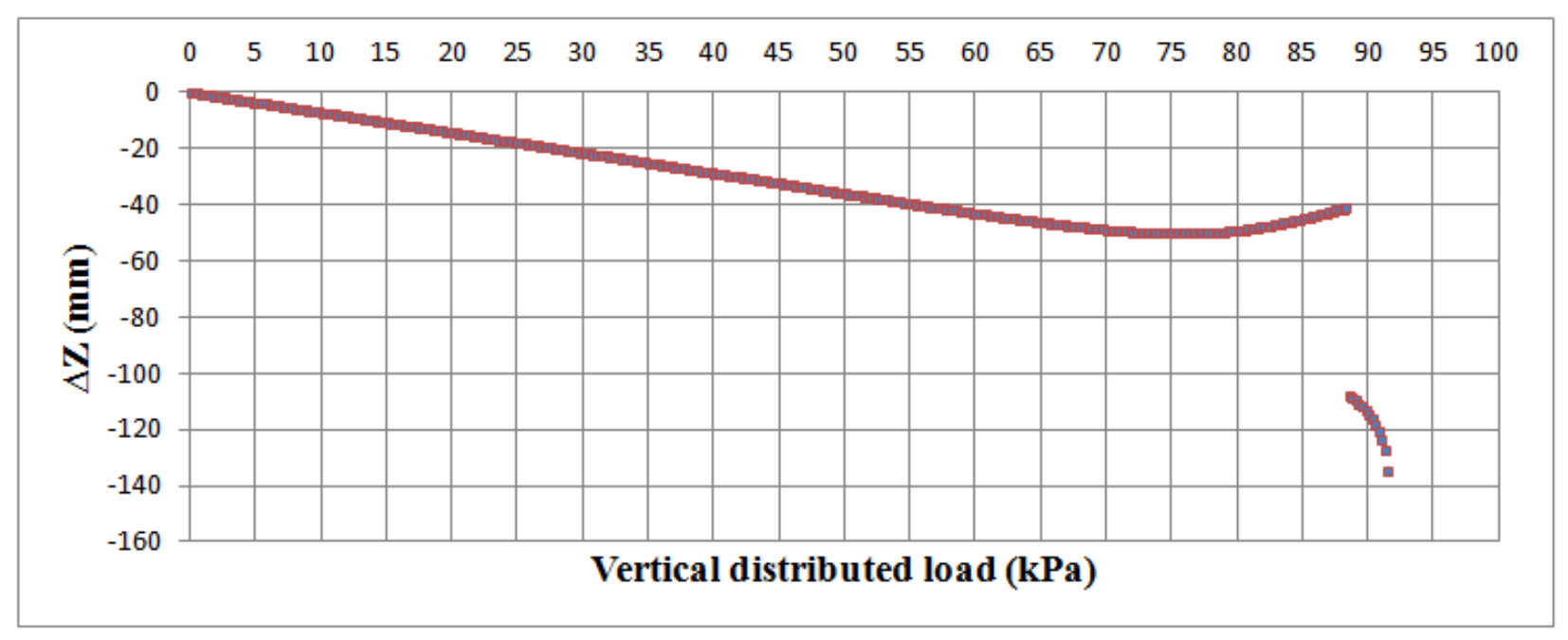

Fig 9. Vertical deformation of the center point -Nonlinear analysis- Dome 7 


\subsection{Boundary Conditions effect}

The effect of fixity of the abutment of the domes is studied for all the cases, considering the abutment fixed for rotation and movement (Fix), fixed for movement and free to rotate (Hinge), and just fixed for vertical movement (Z).

Based on the results (Table 4), rotation fixity has negligible effects on the buckling pressure resulted from linear analysis. However, getting free horizontal movement fixity and rotation fixity, can reduce the buckling pressure up to 34\%, comparing with the Fix condition.

Table 4. The effect of boundary condition

\begin{tabular}{|c|c|c|c|c|c|}
\hline Model & Fix $(\mathrm{kPa})$ & Hinge $(\mathrm{kPa})$ & $\mathrm{Z}(\mathrm{kPa})$ & Hinge/Fix (\%) & Z/Fix (\%) \\
\hline 1 & 274.65 & 265.70 & 183.25 & 97 & 67 \\
\hline 2 & 67.26 & 66.27 & 66.59 & 99 & 66 \\
\hline 3 & 317.79 & 304.74 & 210.23 & 96 & 66 \\
\hline 4 & 77.39 & 75.82 & 51.00 & 98 & 66 \\
\hline 5 & 60.9 & 59.57 & 40.08 & 98 & 66 \\
\hline 6 & 70.08 & 68.50 & 46.24 & 98 & 66 \\
\hline 7 & 224.78 & 219.89 & 150.19 & 98 & 67 \\
\hline 8 & 75.83 & 74.34 & 51.16 & 98 & 67 \\
\hline 9 & 63.82 & 62.93 & 43.11 & 99 & 68 \\
\hline 10 & 72.25 & 71.40 & 47.78 & 99 & 66 \\
\hline 11 & 66.52 & 66.00 & 44.02 & 99 & 66 \\
\hline 12 & 75.53 & 74.48 & 49.92 & 99 & 66 \\
\hline 13 & 94.69 & 92.91 & 62.38 & 98 & 66 \\
\hline 14 & 110.38 & 108.69 & 72.67 & 97 & 67 \\
\hline
\end{tabular}




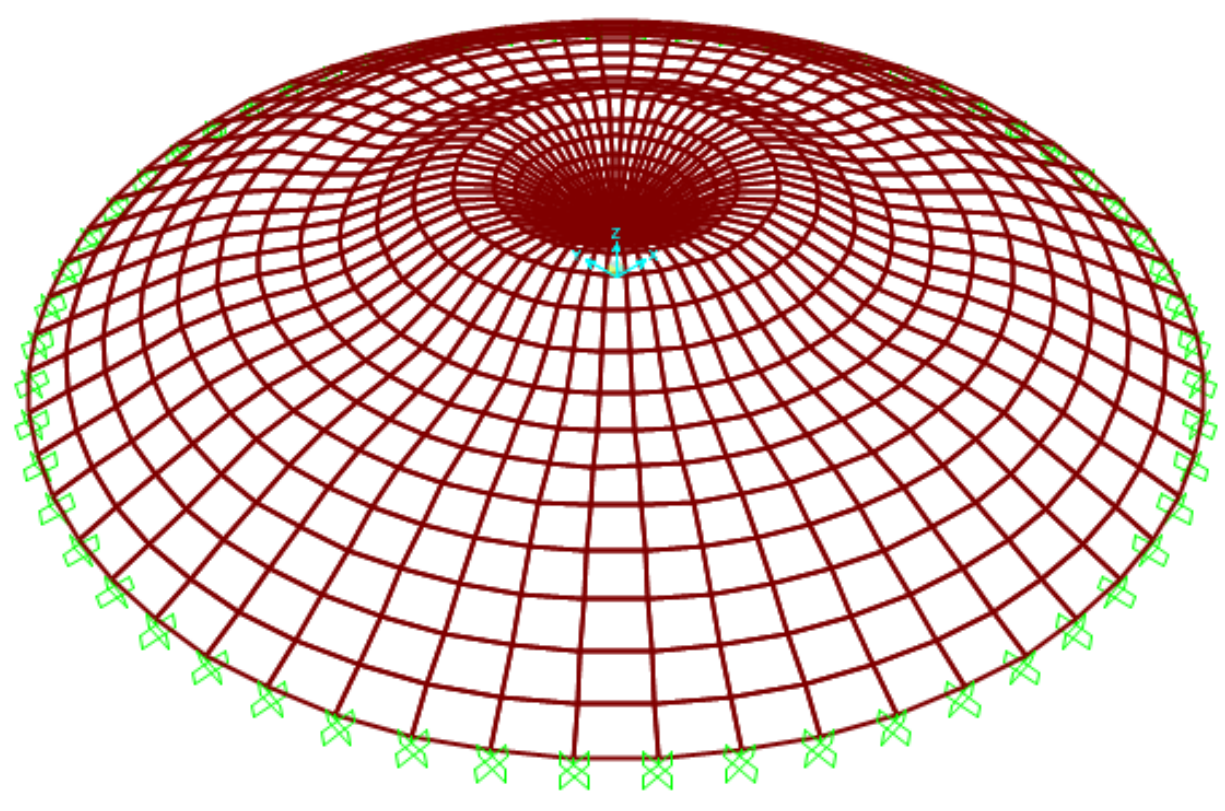

(a) Fixed

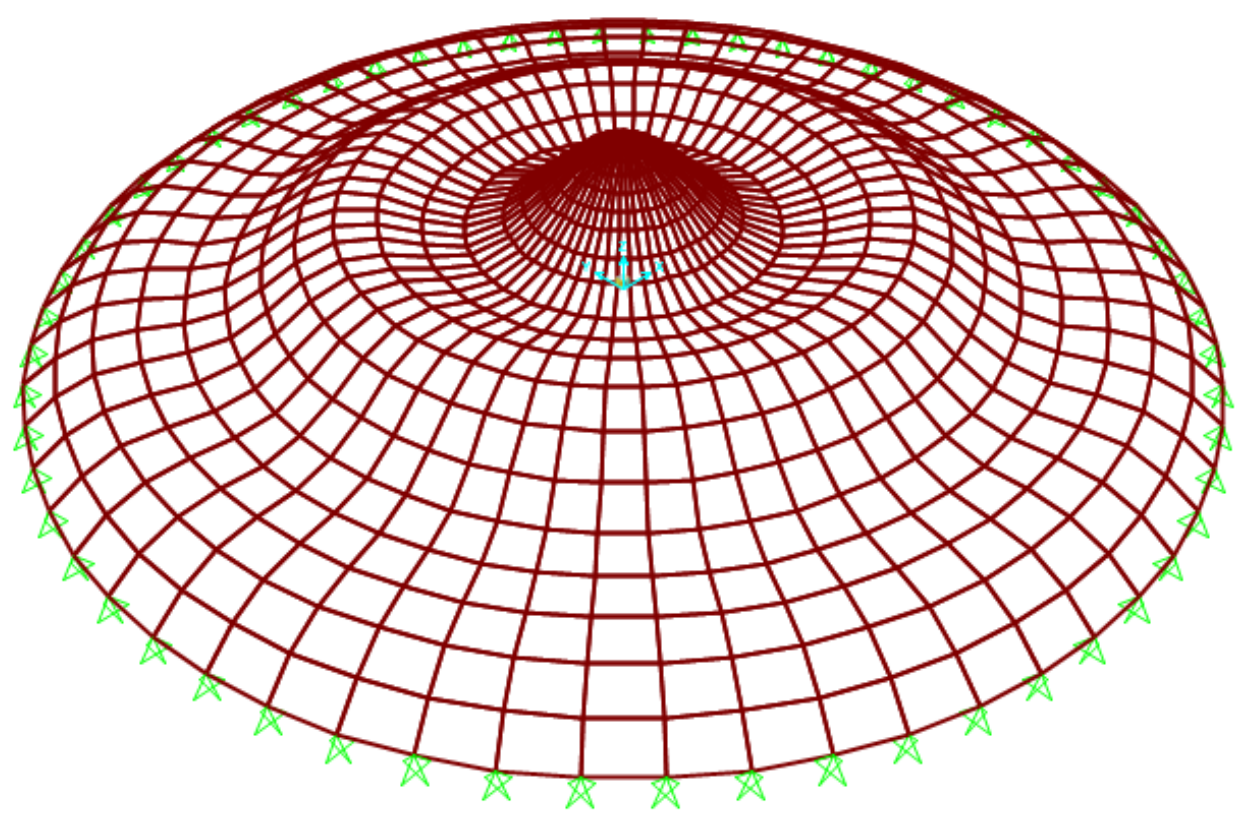

(b) Hinged 


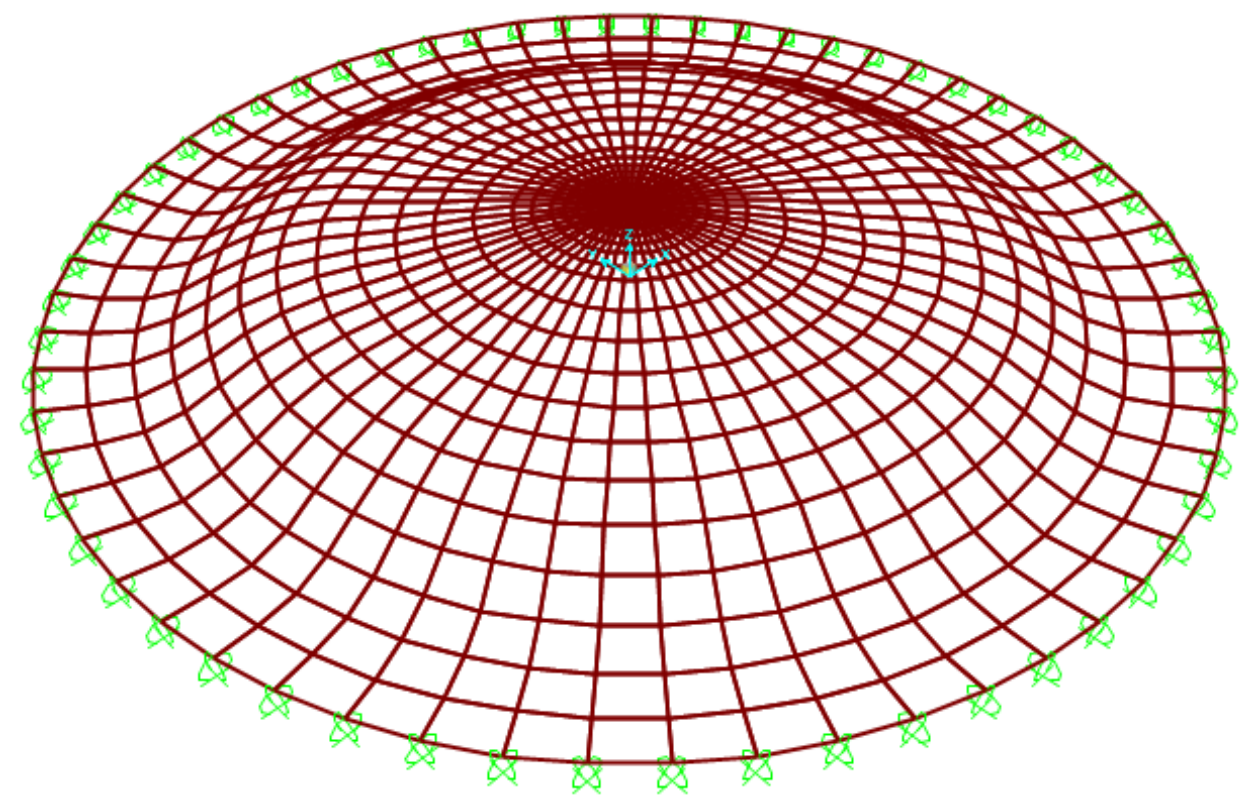

(c)Roller support- Z

Fig 10. Fig 10. First buckling mode under self-weight (DL)- Dome 7

\subsection{Horizontal loading effect}

To study the effect of horizontal loading, such as earthquake, on the maximum pressure that the spherical shells can tolerate before buckling, the effect of horizontal loads on the buckling pressure of spherical shells is analyzed by applying a percentage of self-weight of the domes horizontally by changing horizontal load factor $\left(\mathrm{F}_{\mathrm{EH}}\right)$ from 0.1 to 1 .

The buckling pressure resulted by linear buckling analysis (Fig. 11and 12), with and without considering dead load due to self-weight of the domes, are presented in Table 5. 


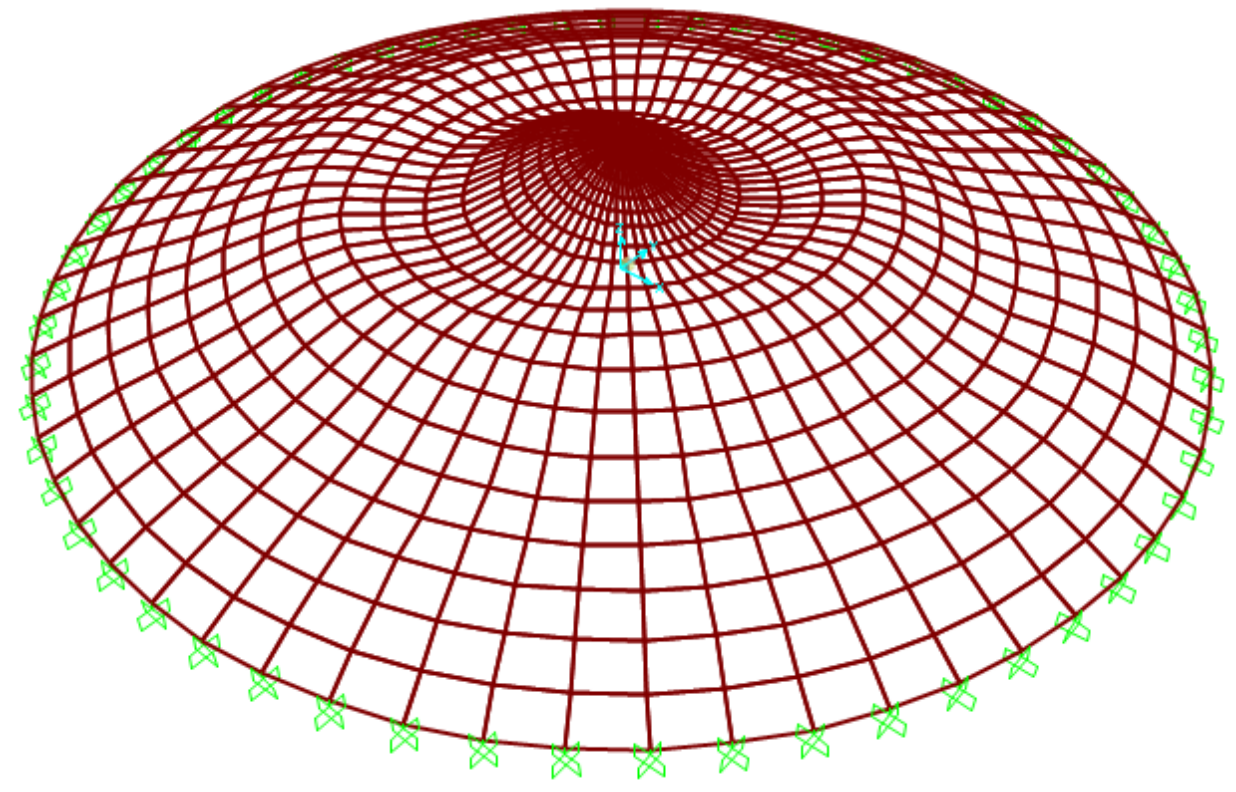

Fig 11. First buckling mode under $\mathrm{DL}+\mathrm{Eh}$

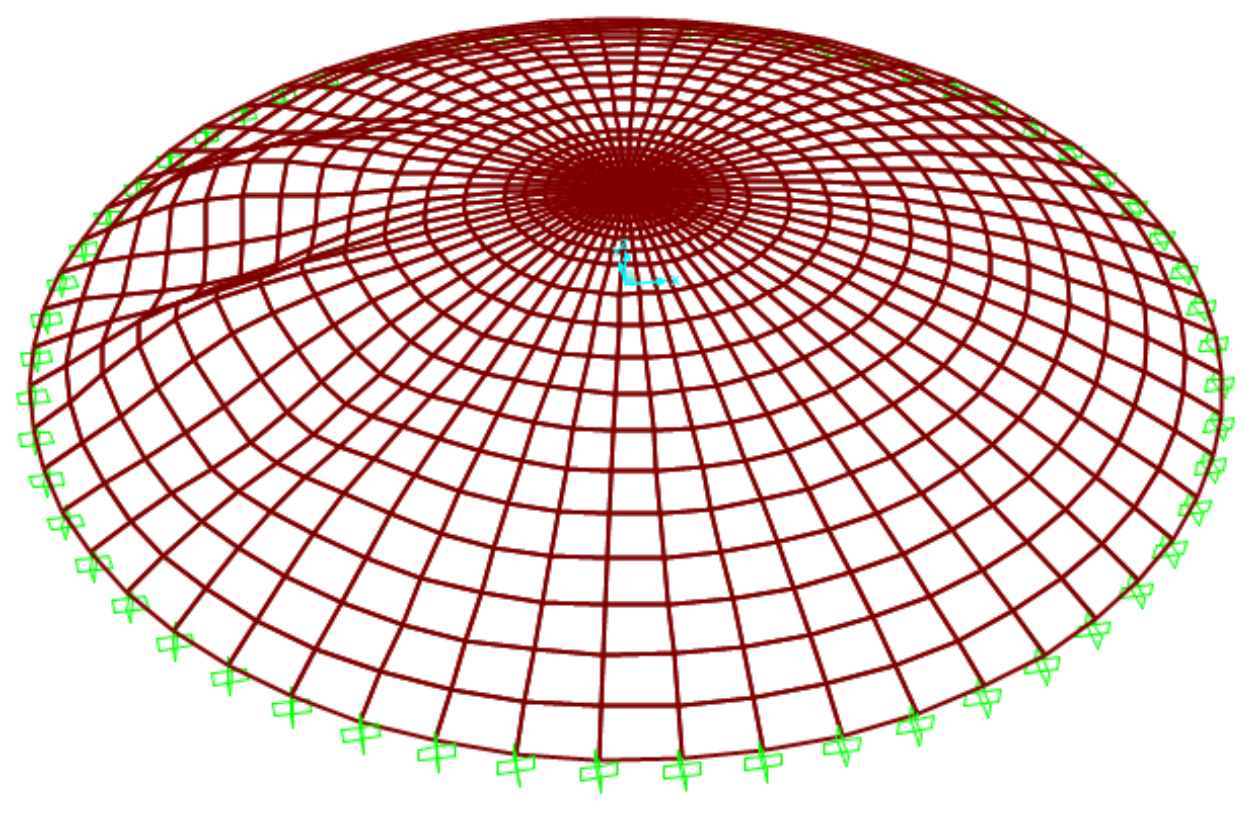

Fig 12. First buckling mode under $E_{h}$ 
Table 5. Resulted buckling pressure applying $E_{h}$ and $\mathbf{D L}+\mathbf{E}_{\mathbf{h}}$

\begin{tabular}{|c|c|c|c|c|c|c|c|}
\hline \multirow{2}{*}{ Case No. } & \multirow{2}{*}{ Load } & \multicolumn{6}{|c|}{$\mathrm{F}_{\mathrm{EH}}$} \\
\hline & & 1 & 0.5 & 0.4 & 0.3 & 0.1 & 0 \\
\hline & $\mathrm{E}_{\mathrm{h}}$ & 523.70 & 1047.39 & 1309.24 & 1745.65 & 5236.94 & - \\
\hline & $\mathrm{DL}+\mathrm{E}_{\mathrm{h}}$ & 217.81 & 254.16 & 261.58 & 268.47 & 287.82 & 274.65 \\
\hline & $\mathrm{E}_{\mathrm{h}}$ & 165.45 & 330.89 & 413.63 & 551.50 & 1654.49 & - \\
\hline & $\mathrm{DL}+\mathrm{E}_{\mathrm{h}}$ & 51.44 & 60.66 & 62.88 & 65.23 & 67.18 & 67.26 \\
\hline & $\mathrm{E}_{\mathrm{h}}$ & 795.63 & 1591.28 & 1989.10 & 2652.13 & 7956.38 & - \\
\hline & $\mathrm{DL}+\mathrm{E}_{\mathrm{h}}$ & 240.72 & 281.10 & 290.50 & 300.29 & 316.49 & 317.79 \\
\hline & $\mathrm{E}_{\mathrm{h}}$ & 175.62 & 351.25 & 439.07 & 585.43 & 1756.30 & - \\
\hline & $\mathrm{DL}+\mathrm{E}_{\mathrm{h}}$ & 58.00 & 69.19 & 71.92 & 74.86 & 79.09 & 77.39 \\
\hline & $\mathrm{E}_{\mathrm{h}}$ & 137.36 & 274.72 & 343.42 & 457.89 & 1373.69 & - \\
\hline & $\mathrm{DL}+\mathrm{E}_{\mathrm{h}}$ & 45.81 & 54.78 & 56.99 & 59.35 & 60.83 & 60.90 \\
\hline & $\mathrm{E}_{\mathrm{h}}$ & 158.58 & 317.12 & 396.41 & 528.55 & 1585.69 & - \\
\hline & $\mathrm{DL}+\mathrm{E}_{\mathrm{h}}$ & 52.59 & 62.79 & 65.28 & 67.99 & 69.99 & 70.08 \\
\hline & $\mathrm{E}_{\mathrm{h}}$ & 188.52 & 377.03 & 471.28 & 628.37 & 1885.14 & - \\
\hline & $\mathrm{DL}+\mathrm{E}_{\mathrm{h}}$ & 111.01 & 156.29 & 169.95 & 185.99 & 223.63 & 224.78 \\
\hline & $\mathrm{E}_{\mathrm{h}}$ & 130.46 & 260.94 & 326.16 & 434.89 & 1304.66 & - \\
\hline & $\mathrm{DL}+\mathrm{E}_{\mathrm{h}}$ & 53.27 & 66.64 & 70.11 & 73.87 & 75.68 & 75.83 \\
\hline & $E_{h}$ & 53.97 & 107.95 & 134.93 & 179.92 & 601.26 & - \\
\hline & $\mathrm{DL}+\mathrm{E}_{\mathrm{h}}$ & 32.49 & 46.16 & 50.35 & 55.27 & 63.64 & 63.82 \\
\hline & $\mathrm{E}_{\mathrm{h}}$ & 101.96 & 203.89 & 270.44 & 339.84 & 1019.51 & - \\
\hline & $\mathrm{DL}+\mathrm{E}_{\mathrm{h}}$ & 48.46 & 63.07 & 66.98 & 70.95 & 72.11 & 72.25 \\
\hline & $E_{h}$ & 94.13 & 188.27 & 235.35 & 313.81 & 941.44 & - \\
\hline & $\mathrm{DL}+\mathrm{E}_{\mathrm{h}}$ & 44.76 & 58.29 & 61.93 & 65.43 & 66.41 & 66.52 \\
\hline & $\mathrm{E}_{\mathrm{h}}$ & 33.85 & 67.70 & 84.61 & 112.81 & 338.45 & - \\
\hline & $\mathrm{DL}+\mathrm{E}_{\mathrm{h}}$ & 25.78 & 41.43 & 47.13 & 54.53 & 74.83 & 75.53 \\
\hline & $\mathrm{E}_{\mathrm{h}}$ & 132.51 & 265.02 & 331.28 & 441.69 & 1325.11 & - \\
\hline & $\mathrm{DL}+\mathrm{E}_{\mathrm{h}}$ & 62.79 & 81.75 & 86.85 & 92.50 & 94.46 & 94.69 \\
\hline & $\mathrm{E}_{\mathrm{h}}$ & 154.04 & 308.03 & 385.03 & 513.39 & 1540.22 & - \\
\hline & $\mathrm{DL}+\mathrm{E}_{\mathrm{h}}$ & 72.89 & 94.87 & 100.82 & 107.40 & 110.32 & 110.38 \\
\hline
\end{tabular}


The resulted buckling of the domes by applying just horizontal component of earthquake $\left(E_{h}\right)$, ignoring the self-weight of the domes, indicates that $E_{h}$ can develop buckling in the spherical concrete with or without applying the self-weight.

Based on the results for applying 30\% of the self-weight of the domes horizontally, as horizontal component of earthquake, combined with self-weight has reduced the buckling resistance of the domes up to $28 \%$, in comparison with the resulted buckling pressure due to self-weight only.

The graphs in Fig. 13 to 19 show the effect of applied horizontal load, without considering the dead load due to self-weight of structure, on buckling pressure.

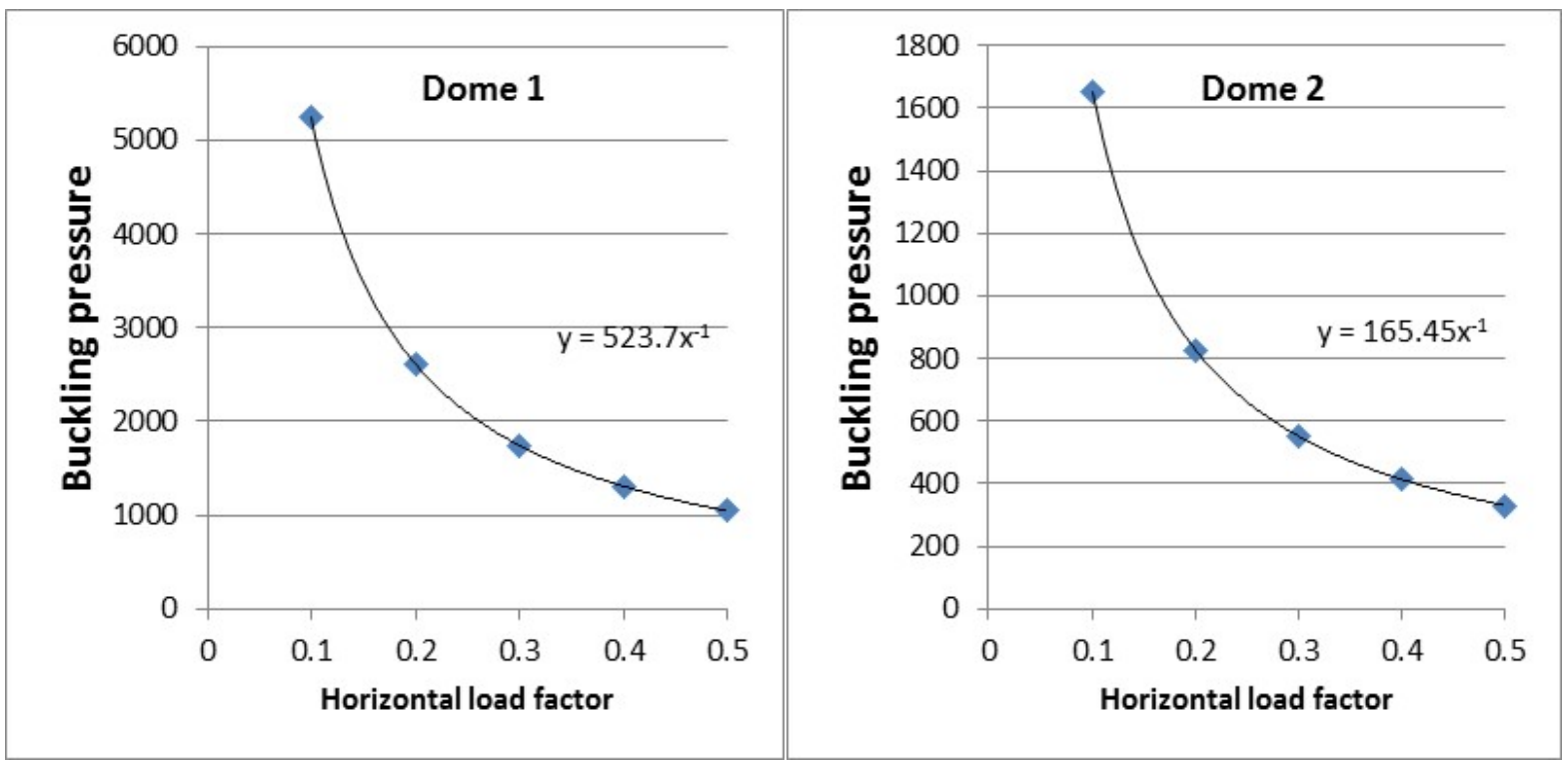

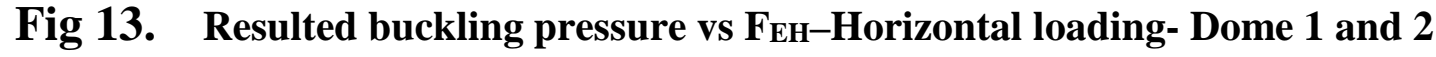




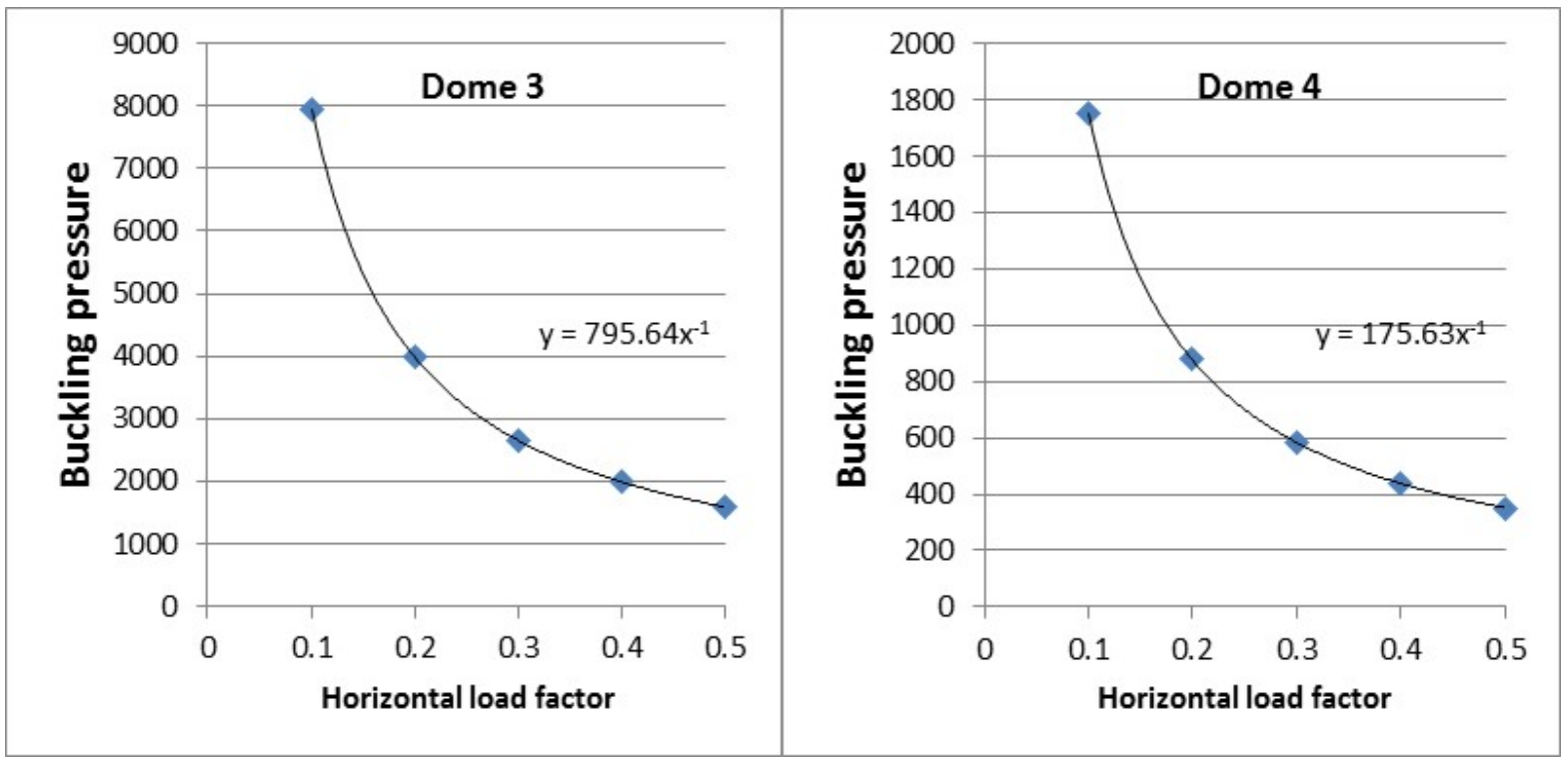

Fig 14. Resulted buckling pressure vs Fен-Horizontal loading- Dome 3 and 4

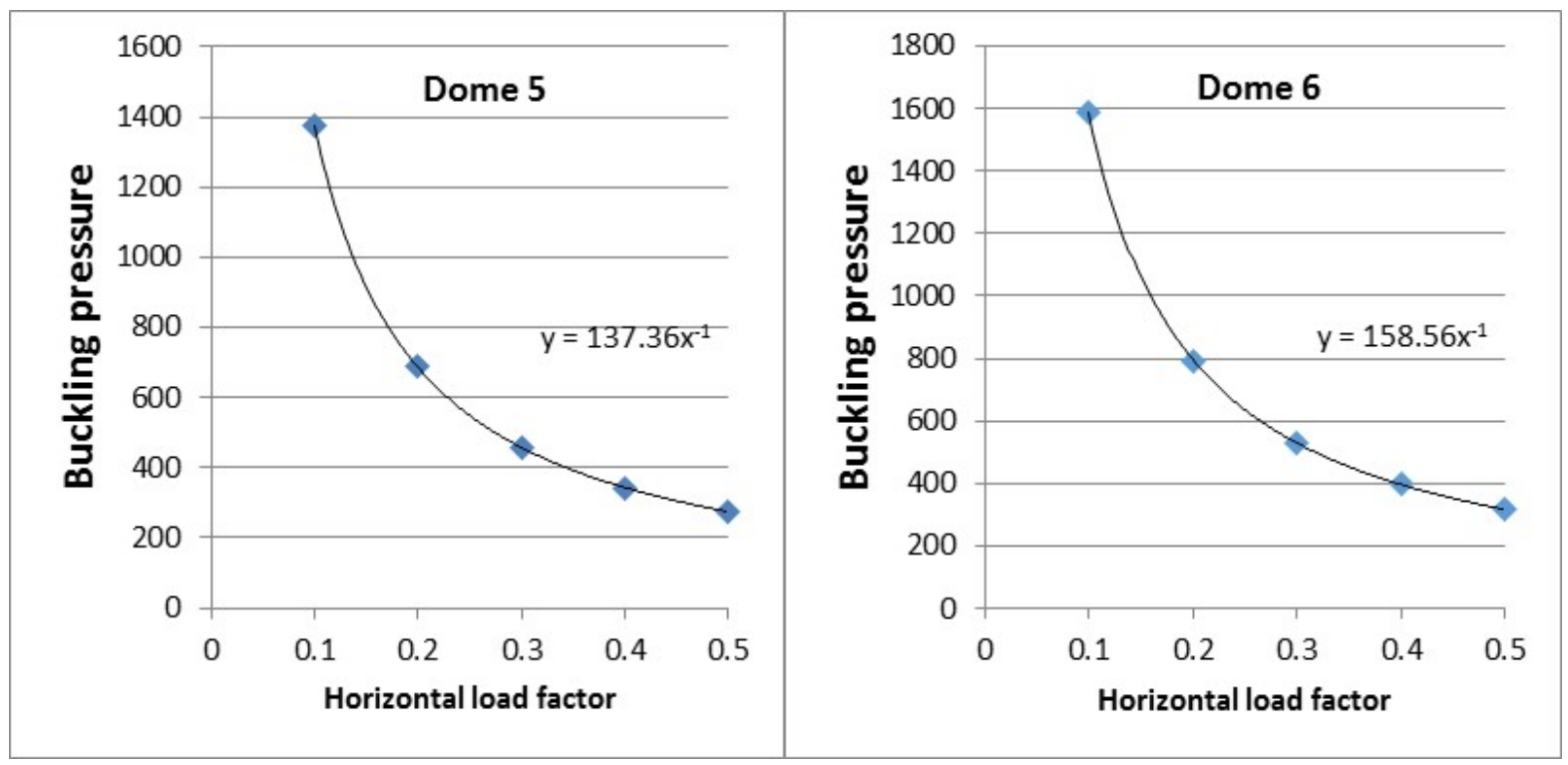

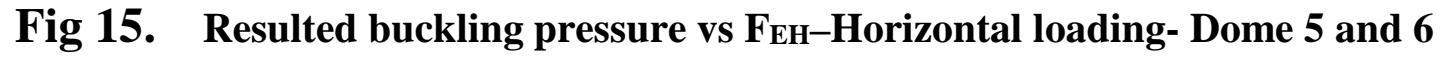




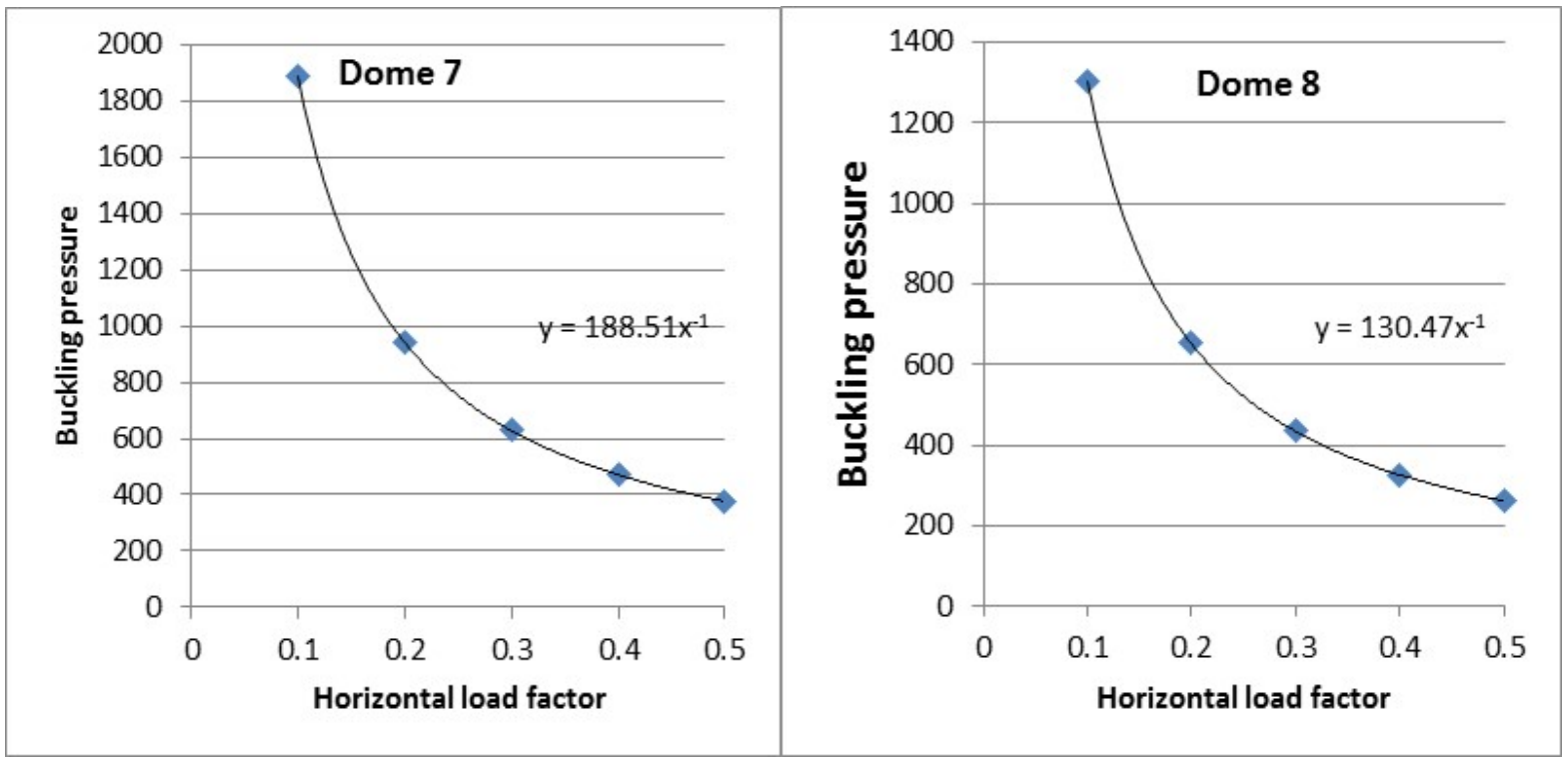

Fig 16. Resulted buckling pressure vs FeH-Horizontal loading- Dome 7 and 8
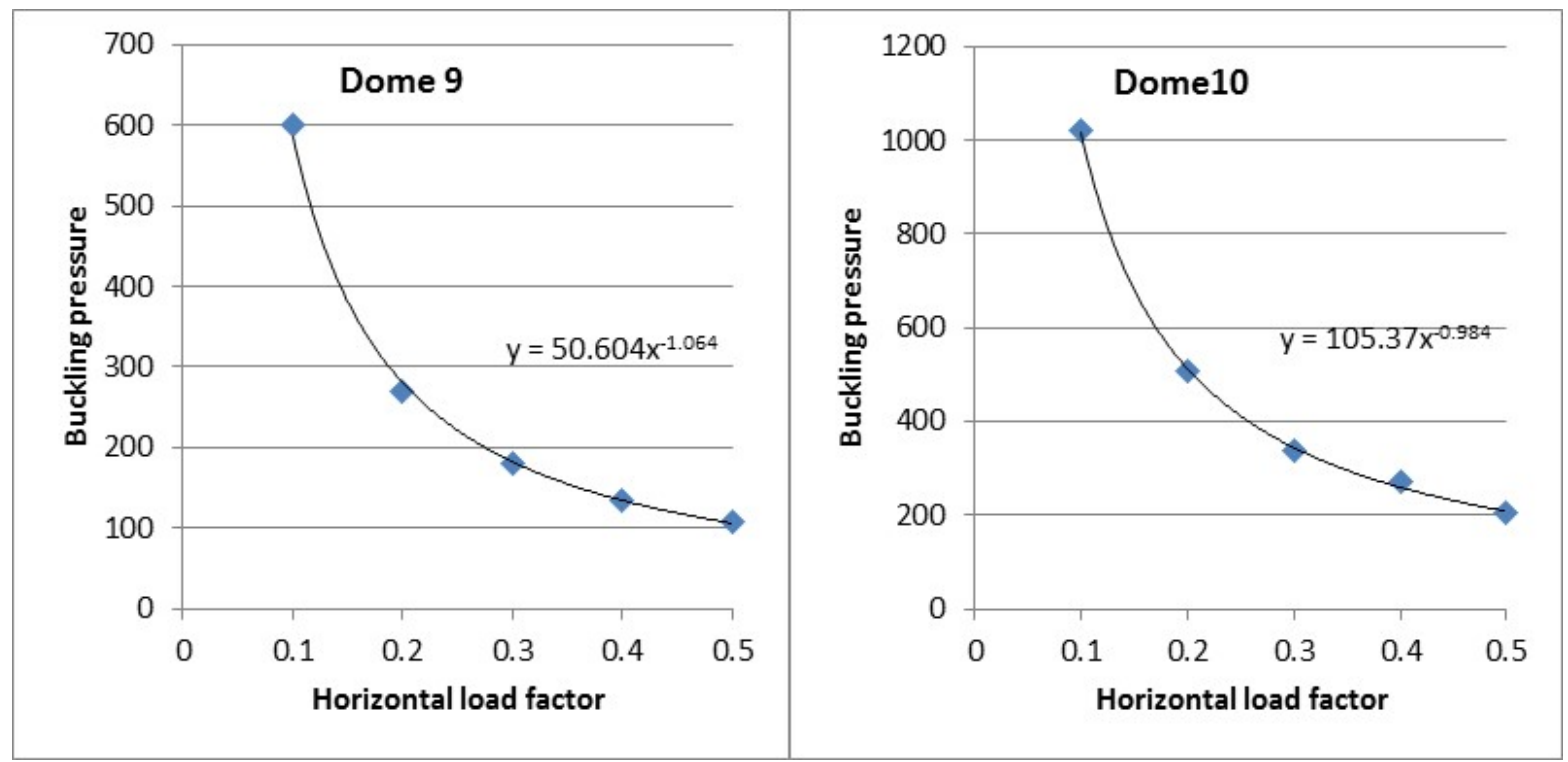

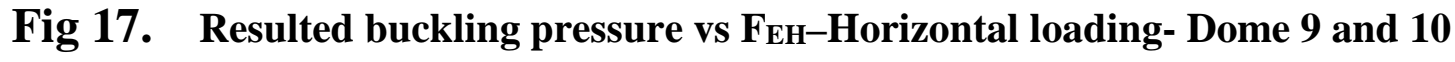



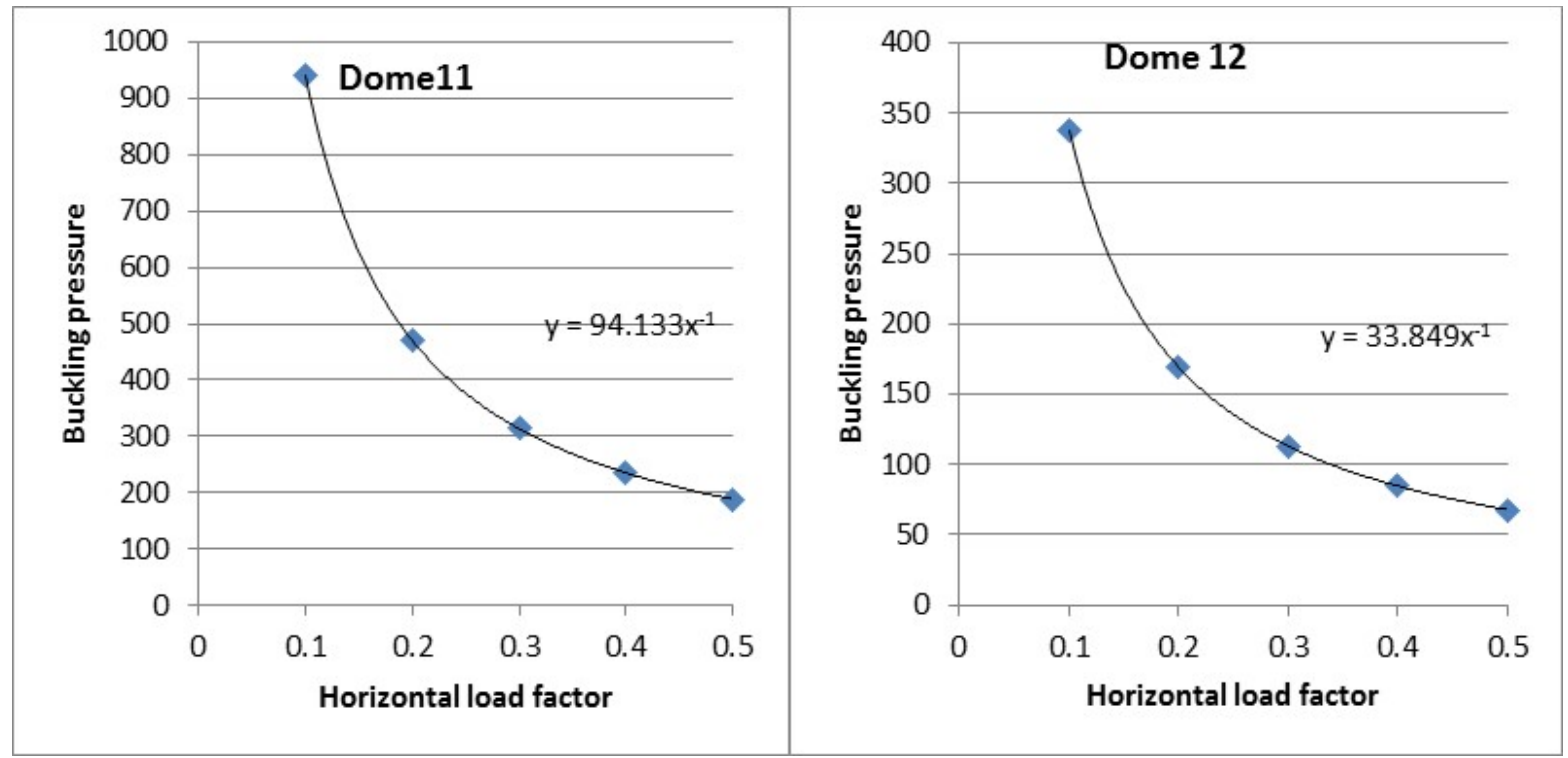

Fig 18. Resulted buckling pressure vs FEH-Horizontal loading- Dome 11 and 12
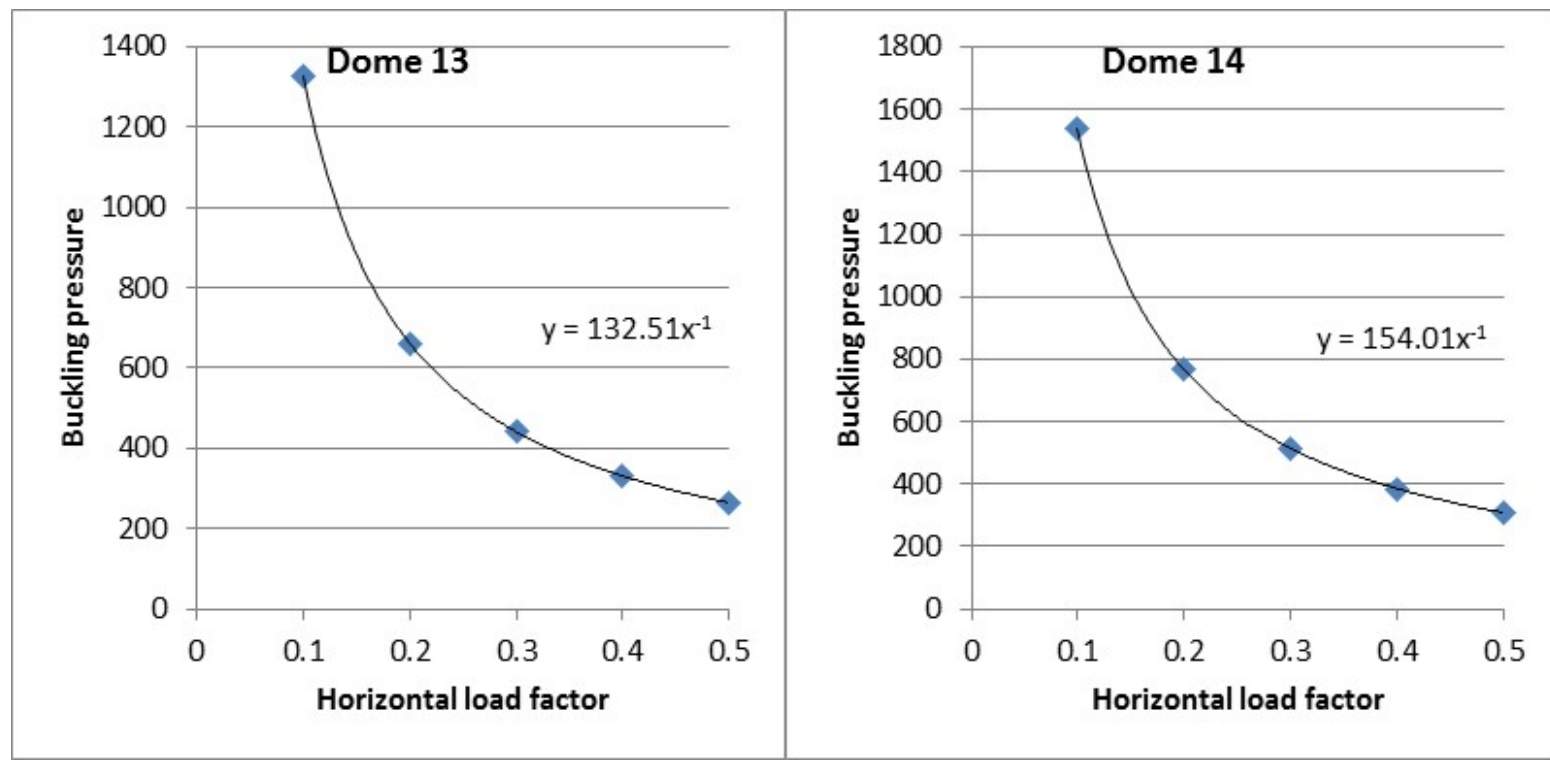

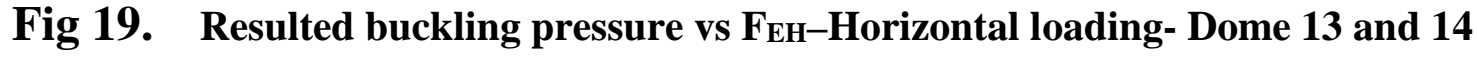


As shown in the graphs above, we can define the resulted buckling pressure due to the horizontal loading, as a simple power function of the horizontal load factor for each case.

Based on the analysis of spherical domes, applying just horizontal component of earthquake $\left(\mathrm{E}_{\mathrm{h}}\right)$, ignoring self-weight of the domes, the buckling pressure may be calculated as;

$$
\text { buckling pressure }=\frac{\mathrm{K}_{1}}{\mathrm{~F}_{\mathrm{EH}}} \quad[E q \text { 13] }
$$

Where:

$\mathrm{F}_{\mathrm{EH}}$ : Horizontal load factor

h: Thickness of the spherical shell

$\mathrm{K}_{1}$ : Factor (Table 6)

Table 6. Resulted $\mathrm{K}_{\mathbf{1}}$-Linear analysis applying $\mathbf{E}_{\mathbf{h}}$

\begin{tabular}{|c|c|}
\hline Case No. & $\mathrm{K}_{1}$ \\
\hline 1 & 523.7 \\
\hline 2 & 165.5 \\
\hline 3 & 795.6 \\
\hline 4 & 175.6 \\
\hline 5 & 137.4 \\
\hline 6 & 158.6 \\
\hline 7 & 188.2 \\
\hline 8 & 130.5 \\
\hline 9 & 54 \\
\hline 10 & 105.4 \\
\hline 11 & 94.1 \\
\hline 12 & 33.8 \\
\hline 13 & 132.5 \\
\hline 14 & 154 \\
\hline
\end{tabular}


The effect of applying horizontal load, combined with the dead load due to selfweight of structure on buckling pressure, are presented in the graphs in Fig 20 to 26.

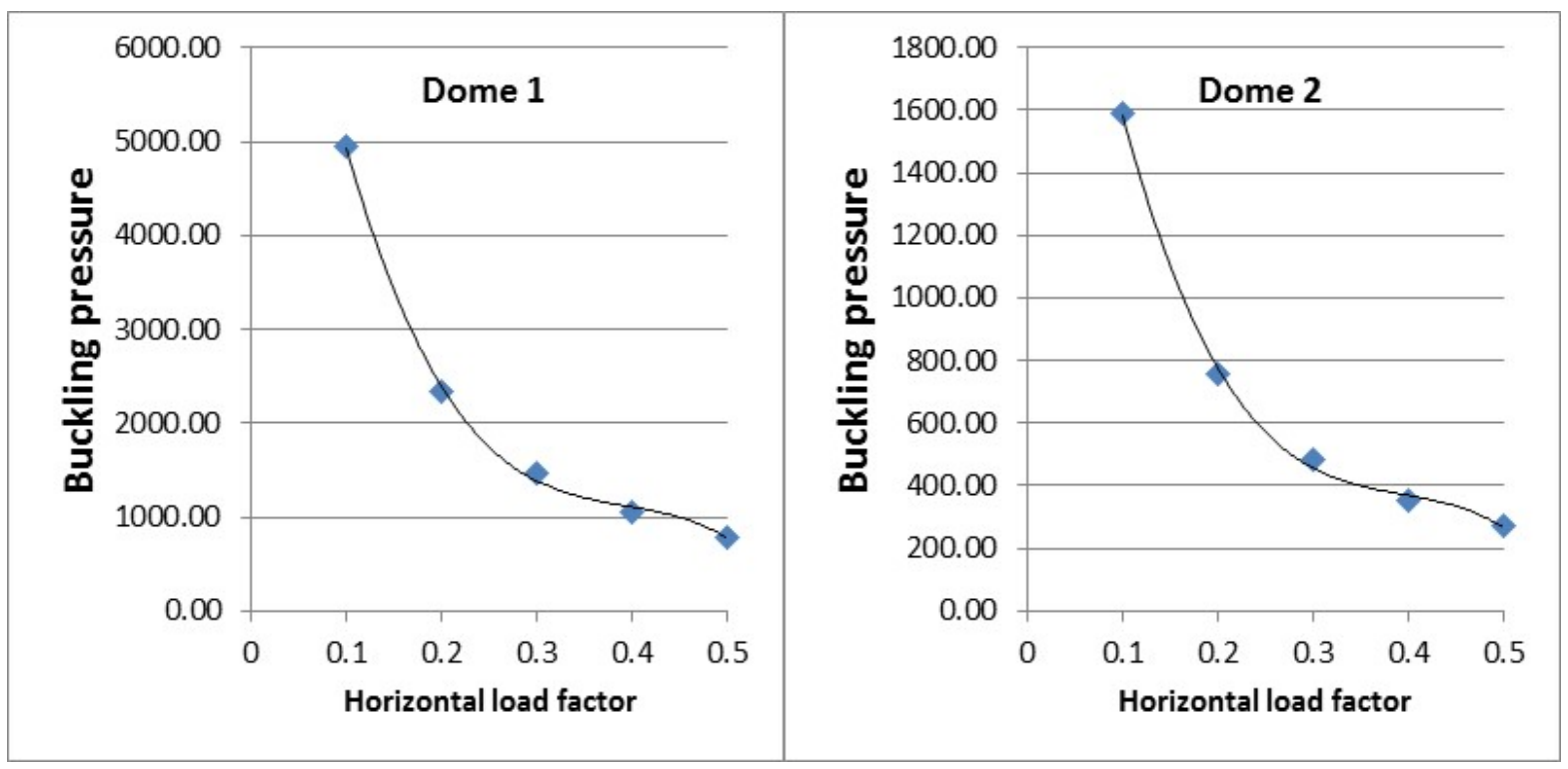

Fig 20. Resulted buckling pressure vs $F_{E H}$-Horizontal loading + Self-weight

Dome 1 and 2

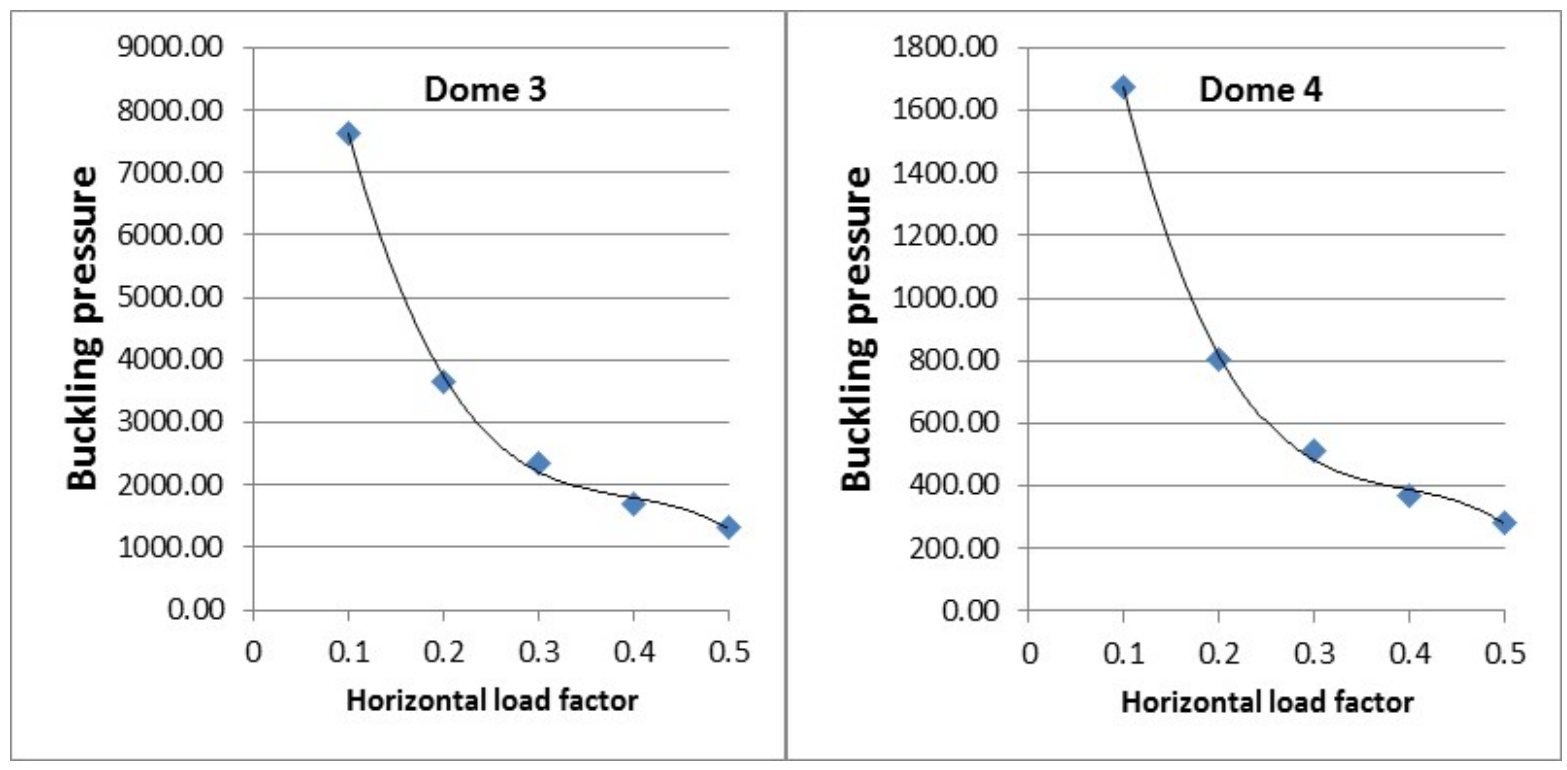

Fig 21. Resulted buckling pressure vs FEH $_{\mathrm{EH}}$-Horizontal loading + Self-weight

Dome 3 and 4 


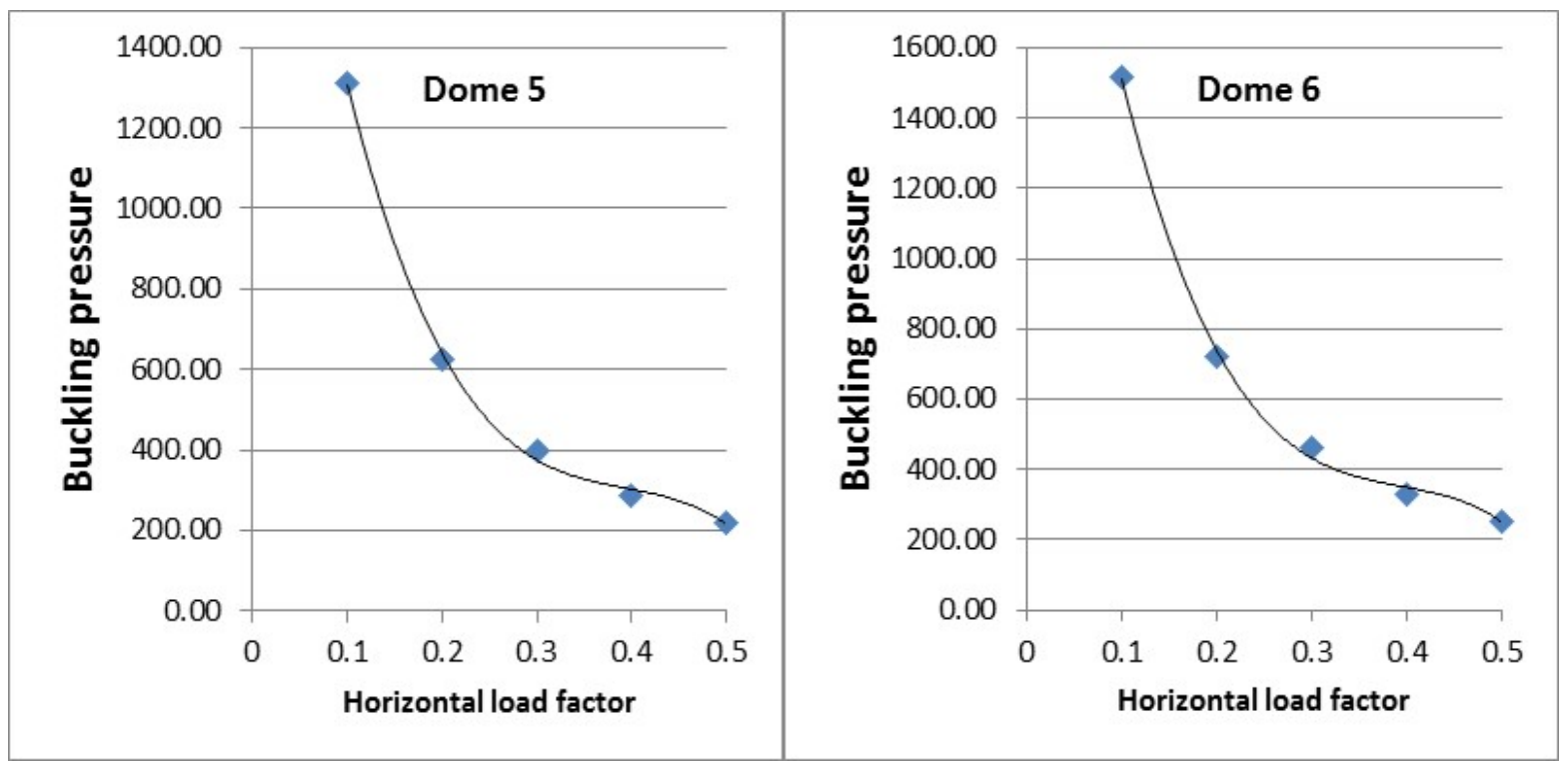

Fig 22. Resulted buckling pressure vs $\mathbf{F}_{\mathrm{EH}}$-Horizontal loading + Self-weight

Dome 5 and 6

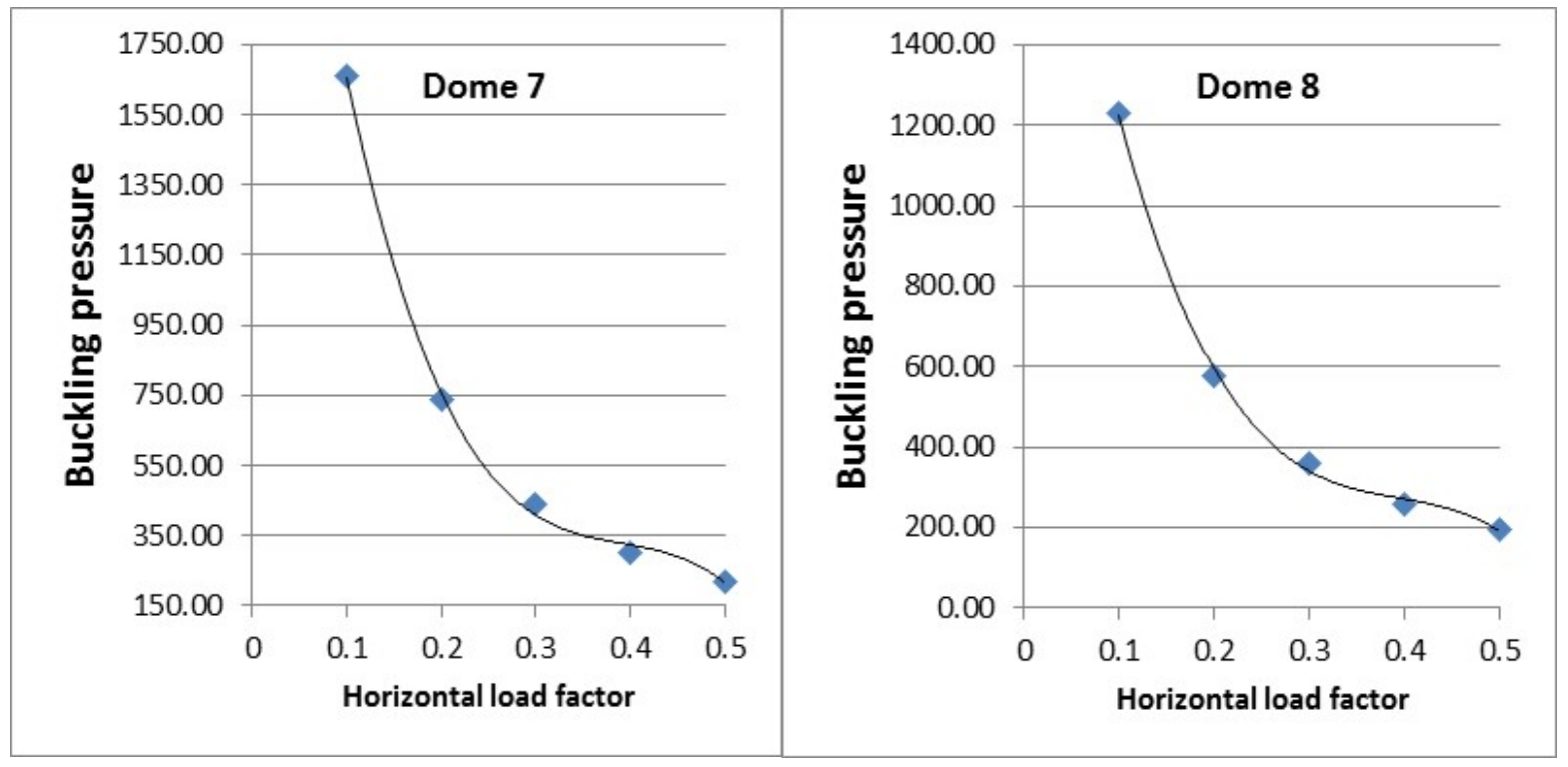

Fig 23. Resulted buckling pressure vs $\mathbf{F}_{\mathrm{EH}}$-Horizontal loading + Self-weight

Dome 7 and 8 


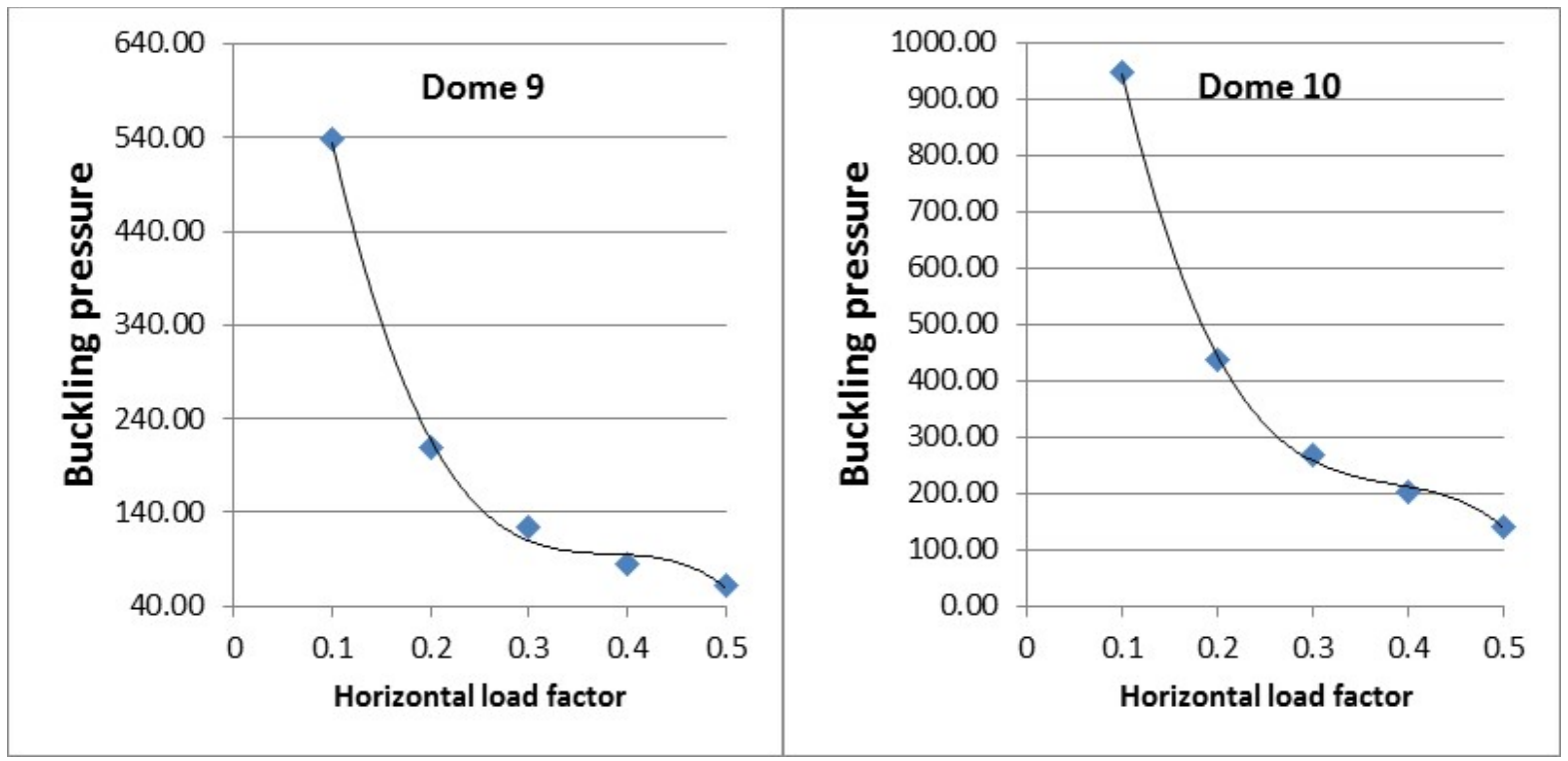

Fig 24. Resulted buckling pressure vs FEH-Horizontal loading + Self-weight Dome 9 and 10

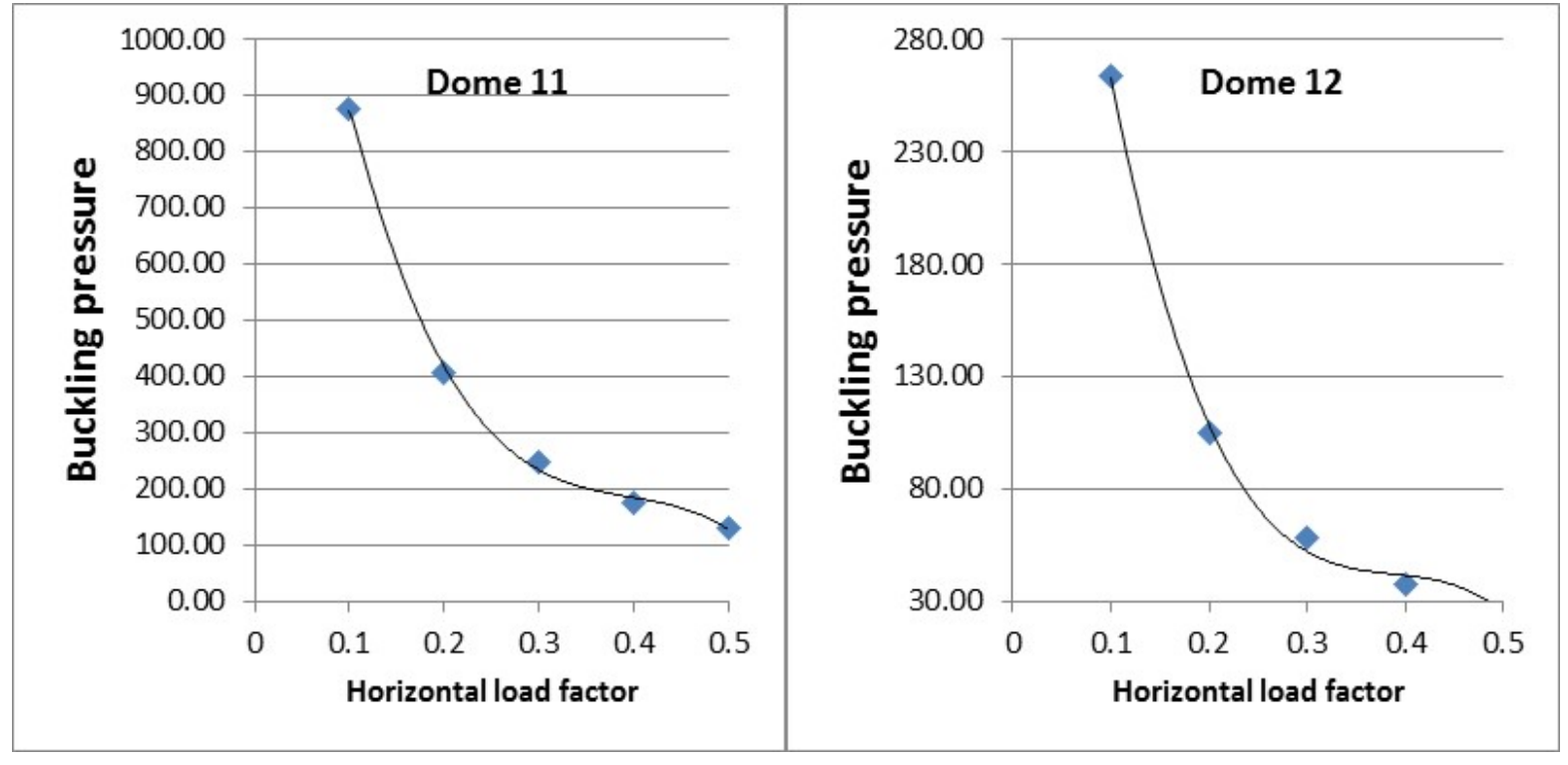

Fig 25. Resulted buckling pressure vs FEH $_{E H}$ Horizontal loading + Self-weight

Dome 11 and 12 


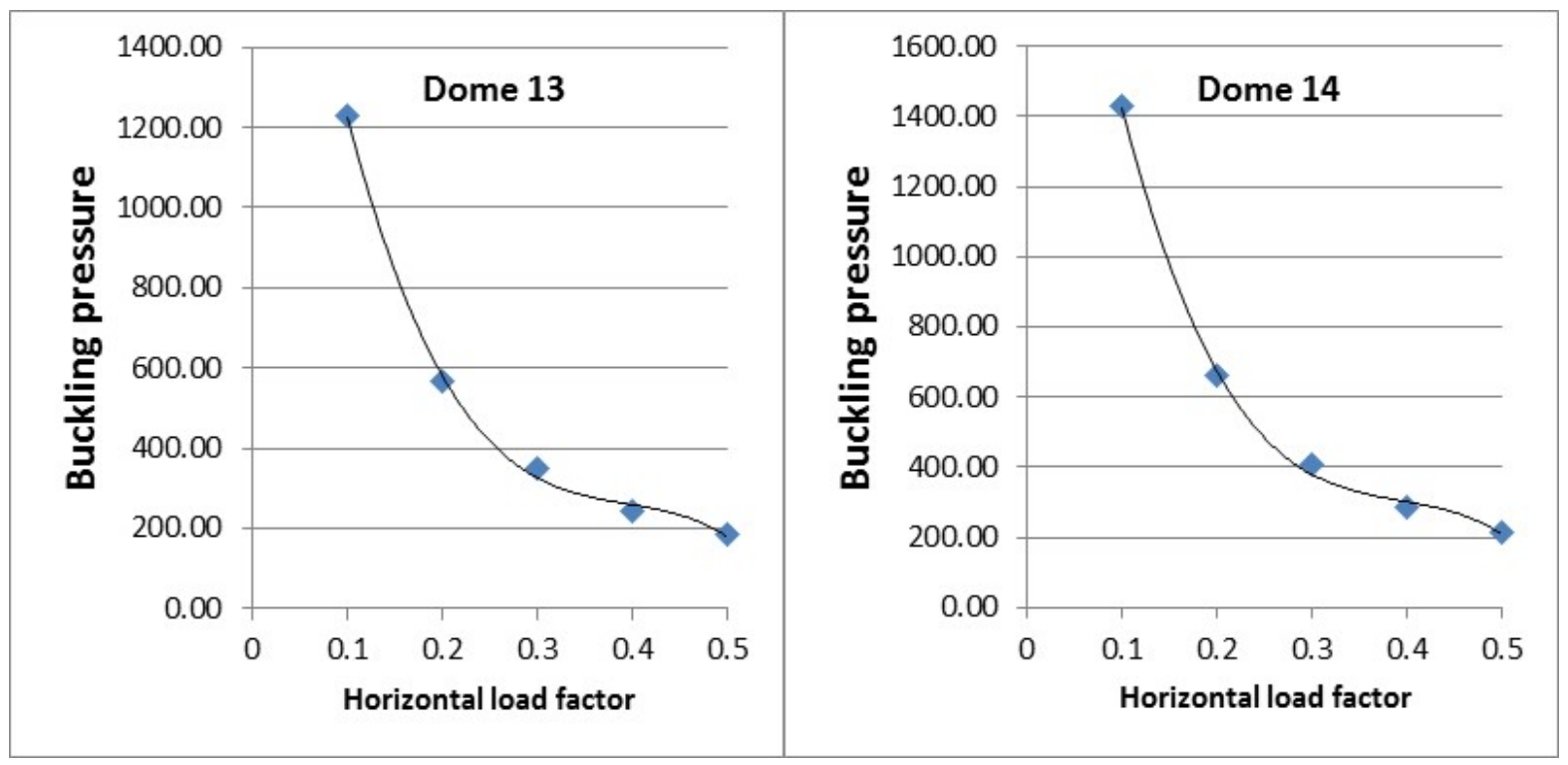

Fig 26. Resulted buckling pressure vs FEH-Horizontal loading + Self-weight Dome

\section{3 and 14}

In the case of applying the horizontal load combined with the self-weight of the shells, a polynomial trend-line that fit with the results as shown in Fig 20 to 26.

However, considering the variation of the horizontal load factor from 0.2 to 0.4 , we can define the resulted buckling pressure due to the horizontal loading combined with the self-weight, as a simple power function of the horizontal load factor for each case.

Based on the linear analysis of spherical domes, applying just horizontal component of earthquake $\left(\mathrm{E}_{\mathrm{h}}\right)$, combined with the self-weight of the domes, the buckling pressure may be calculated as;

$$
\text { buckling pressure }=\frac{\mathrm{K}_{2}}{\mathrm{~F}_{\mathrm{EH}}} \quad[E q \text { 14 }]
$$

Where:

$\mathrm{K}_{2}$ : Factor (Table 7) 
Table 7. Resulted $\mathbf{K}_{2}-$ Linear analysis applying $\mathbf{D L}+\mathbf{E}_{\mathbf{h}}$

\begin{tabular}{|c|c|c|}
\hline Case No. & $\mathrm{K}_{2}$ & $\mathrm{~K}=\mathrm{K}_{1}-\mathrm{K}_{2}$ \\
\hline 1 & 450 & 73.70 \\
\hline 2 & 146 & 19.50 \\
\hline 3 & 705 & 90.60 \\
\hline 4 & 153 & 22.60 \\
\hline 5 & 120 & 17.40 \\
\hline 6 & 138 & 20.60 \\
\hline 7 & 133 & 55.20 \\
\hline 8 & 108 & 22.50 \\
\hline 9 & 37 & 17.00 \\
\hline 10 & 80 & 25.40 \\
\hline 11 & 74 & 20.10 \\
\hline 12 & 17 & 16.80 \\
\hline 13 & 105 & 27.50 \\
\hline 14 & 122 & 32.00 \\
\hline
\end{tabular}

Based on the graph, factor K can be estimated as a function of $\left(\frac{h}{R}\right)^{2}$ :

$$
K=9.4\left(\frac{h}{R}\right)^{2}+0.6 \quad[E q 15]
$$

Finally, based on linear FE analysis on the discussed cases, the final elastic buckling pressure for clamped spherical concrete shells under vertical and horizontal loading may be calculated as:

$$
P_{0}=\frac{2 E\left(\frac{h}{R}\right)^{2}}{\sqrt{3\left(1-v^{2}\right)}}-\frac{9.4\left(\frac{h}{R}\right)^{2}+0.6}{\mathrm{~F}_{\mathrm{EH}}} \quad[E q \text { 16] }
$$

\section{Conclusion and suggestions}

In this study buckling analysis is performed using the Finite Element Method. The buckling behavior of several dome configurations with different geometry is investigated. 
An equation is proposed to calculate the dome buckling. The results of finite element analysis for vertical loads closely coincide with the analytical solution.

Based on the results of the FE analysis, it is shown that, geometric nonlinearity widely affects the buckling resistance of the spherical shells.

The results of this study show that horizontal loads have a major effect on buckling pressure. However, in the current recommended equation by The American Concrete Institute (ACI 372R-13) to design spherical concrete shells against buckling this effect is ignored.

To future develop the current study the nonlinear analysis for the spherical domes under horizontal loading with different abutment condition could be considered.

The effect of concrete material non-linearity on buckling spherical shell could be studied using laboratory testing.

In this study, the effect of abutment condition is considered fully fixed, hinged and roller support conditions. To consider real condition, the abutment can be considered as semi- flexible or by considering the walls of the tank, connected to the domes.

The current study has considered the spherical shells. Domes with variable radius could be considered to future develop the equation to calculate related buckling pressures. 


\section{References}

- Huang, Nai-Chen, "Unsymmetrical Buckling of Thin Shallow Spherical Shells," Division of Engineering and Applied Physics, Harvard University, Cambridge, Massachusetts, 1963

- Krenzke, Martin A., and Thomas J. Kiernan, "The Effect of Initial Imperfections on the Collapse Strength of Deep Spherical Shells”, Report 1757, Model Basin In-house Independent Research Program, 1965

- Bushnell David, "Nonlinear Axisymmetric Behavior of Shells of Revolution," AIAA Journal 5.3, The American Institute of Aeronautics and Astronautics, 432-29, 1966

- Zarghamee, Mehdi S., and Frank J. Heger, "Buckling of Thin Concrete Domes," ACI Journal, 487-500, 1983

- ACI 372R-13, "Guide to Design and Construction of Circular Wire- and Steand- Wrapped Prestressed Concrete Structures,” Reported by ACI Committee 372, 2013

- Timoshenko, Stephen P., and James M. Gere., "Theory of Elastic Stability,” McGraw-Hill Book Company, pp 495-499 and pp 512-519, 1963

- SAP2000 Version 17, 2015, Integrated Software for Structural Analysis \& Design, Computer and Structures Inc, Berkeley, CA, USA. 